\title{
Near-Surface Soil Moisture Assimilation for Quantifying Effective Soil Hydraulic Properties under Different Hydroclimatic Conditions
}

\begin{abstract}
Amor V.M. Ines and Binayak P. Mohanty*
We conducted a validation study of a newly developed near-surface soil moisture assimilation scheme for estimating effective soil hydraulic properties using soil moisture data from different hydroclimatic regions, including semihumid Oklahoma, humid Iowa and Illinois, and temperate humid China. A genetic algorithm (GA) was used to estimate the effective soil water retention $\theta(h)$ and hydraulic conductivity $K(h)$ functions of an effective modeling domain by minimizing errors between observed near-surface soil moisture and values simulated with the Richards-based Soil-Water-Atmosphere-Plant (SWAP) model. The parameter estimation approach considered uncertainties in the initial and bottom boundary conditions, rooting depth, and root density by creating simulation ensembles based on combinations of several modeling conditions and a multipopulation approach in the GA to estimate uncertainties in the derived soil hydraulic properties. The results showed that $\theta(b)$ is not very sensitive to variations in the initial and boundary conditions, rooting depth, and root density applied on the modeling domain. The value of $K(h)$ was found to be more sensitive to variations in rooting depth and root density than to variations in the initial and boundary conditions. With the modeling domain better represented, the estimated $\theta(h)$ and $K(h)$ functions were found to be satisfactory in most of the locations studied. They were validated using laboratory-measured $\theta(b)$ and $K_{\text {sat' }}$, observed soil moisture in the field, and soil hydraulic properties from the UNSODA database. Our study indicates, however, that the homogeneous-medium assumption commonly used to effectively describe a heterogeneous system may fail to closely represent a highly heterogeneous (layered) soil profile if only the near-surface soil moisture data are used to define the subsurface soil hydraulic properties. Additional soil moisture data from deeper depths may be needed to better estimate the effective soil hydraulic properties of highly heterogeneous systems.
\end{abstract}

AbBREVIATIONS: DOY, day of the year; ET, evapotranspiration; GA, genetic algorithm; MBE, mean bias error; SCAN, Soil Climate Analysis Network; SMEX02, Soil Moisture Experiment 2002; SPG97, Southern Great Plains 1997; SWAP, Soil-Water-Atmosphere-Plant model; TDR, time domain reflectometry.

$S_{\text {at }}^{\circ}$ il hydraulic parameters are essential input to most hydrologic and climatic models (Mohanty et al., 2002; Mohanty and Zhu, 2007). They are used to define the hydraulic characteristics of the soil vital in modeling soil moisture and flux in the unsaturated zone near the land-atmosphere boundary. At the scale of model applications, it is very important to define the appropriate parameter values to characterize the effective hydraulic behavior of the soil system (Wood, 1994; Vrugt et al., 2004). These so-called effective soil hydraulic parameters (Zhu and Mohanty, 2003; Jhorar et al., 2004) are not always available for practical applications.

At the field scale, the effective soil hydraulic properties are usually defined using a bottom-up approach wherein point-scale soil hydraulic data are scaled up using similar media scaling approaches. In these methods, scaling factors are derived and used to define sets of scaled soil hydraulic properties for both $\theta(h)$ and $K(b)$, where $\theta$ is soil moisture, $K$ is hydraulic conductivity, and $h$ is the pressure head (Miller and Miller, 1956; Hopmans and Stricker, 1989; Clausnitzer et al., 1992; Rockhold et al., 1996; Bertuzzi and Bruckler, 1996;

Dep. of Biological and Agricultural Engineering, Texas A\&M Univ., 2117 TAMU, 201 Scoates Hall, College Station, TX 77843. Received 28 Mar. 2007. *Corresponding author (bmohanty@tamu.edu).

Vadose Zone J. 7:39-52

doi:10.2136/vzj2007.0048

(C) Soil Science Society of America

677 S. Segoe Rd. Madison, WI 53711 USA.

All rights reserved. No part of this periodical may be reproduced or transmitted in any form or by any means, electronic or mechanical, including photocopying, recording, or any information storage and retrieval system, without permission in writing from the publisher.
Kabat et al., 1997; Van Dam et al., 1997). Bottom-up approaches like this require extensive soil hydraulic data to establish the reference soil hydraulic functions and the statistical characteristics of the scaling factors, therefore limiting their application in larger scale hydrologic and hydroclimatic modeling. The spatial variability of the soil hydraulic properties within a large climatic model grid can be also accounted for by using appropriate spatial averaging of localscale soil hydraulic parameters (Gomez-Hernandez and Gorelick, 1989; Green et al., 1996; Zhu and Mohanty, 2002, 2003).

In larger-scale hydrologic modeling, the soil system can be considered as an equivalent homogenous unit described by a set of effective soil hydraulic parameters (Feddes et al., 1993a; Wood, 1994). This assumption is attractive to explore since a top-down approach can be developed to estimate these effective parameters based on inversion of remote sensing data. Feddes et al. (1993b) proposed the use of hydrologic variables derived from remote sensing as conditioning criteria for regional inverse modeling to define these effective parameters. Evapotranspiration (ET)-based approaches evolved from this framework (e.g., Jhorar et al., 2002, 2004; Ines and Droogers, 2002a,b) by taking advantage of the improved methodologies in estimating ET from remote sensing data (e.g., Bastiaanssen et al., 2002). Jhorar et al. (2002, 2004) numerically explored the existence of these effective parameters with an ET-based inverse modeling approach in which ET simulated by forward modeling was matched iteratively with ET simulated by inverse modeling using a gradient-based search algorithm to optimize selected sets of soil hydraulic parameters. Despite the broad coverage of their numerical experiments, the goodness-of-fits of the derived soil hydraulic parameters were validated on seasonal 
values of ET, bottom boundary fluxes, $Q$, and changes in total storage, $\Delta S$, rather than the profile soil moisture dynamics, crucial for subseasonal applications such as in agricultural water management. Using lysimeter data, Ines and Droogers (2002a) showed that ETbased soil hydraulic parameters do not always closely reproduce the soil moisture dynamics in a soil profile. They found that the profile soil moisture is more stable as a search criterion for quantifying the soil hydraulic parameters.

Remotely sensed soil moisture data, however, are available only for the top 0 to $5 \mathrm{~cm}$ of the soil surface (Jackson et al., 1995). To test if near-surface soil moisture data can be used to characterize the subsurface soil hydraulic properties, we developed in this study an inverse modeling-based near-surface soil moisture assimilation scheme using evolutionary computing (Goldberg, 1989). Unlike with usual near-surface data assimilation procedures where a shallow soil moisture profile is being retrieved (e.g., Entekhabi et al., 1994; Galantowicz et al., 1999; Walker et al., 2001; Heathman et al., 2003; Crow and Wood, 2003; Dunne and Entekhabi, 2005; Das and Mohanty, 2006), the new method aims to derive the effective soil hydraulic properties of the soil profile. In this study, we validated in the field the near-surface soil moisture assimilation scheme for estimating the effective soil hydraulic properties across the soil profile in different hydroclimatic regions. We conducted validation experiments using field data from Oklahoma, Iowa, and Illinois in the United States and several soil moisture monitoring sites in China. Our study was designed to test a new effective parameter estimation approach under real-world conditions and to evaluate the value of using actual field data, in this case soil moisture, for determining the effective soil hydraulic properties. Our study also aimed to explore possible sources of uncertainties for field conditions not usually accounted for in numerical forward-backward experiments where all simulation conditions are considered to be known (Abbaspour et al., 2000).

\section{Materials and Methods}

\section{Near-Surface Soil Moisture Assimilation Scheme}

The inverse modeling-based near-surface soil moisture assimilation scheme was implemented by combining a physically based Soil-Water-Atmosphere-Plant model, SWAP (Van Dam et al., 1997), with a genetic algorithm, GA (Goldberg, 1989). The criterion for estimating the effective soil hydraulic properties is given by near-surface $(0-5-\mathrm{cm})$ soil moisture data. The method can also accommodate ET as conditioning data, which can be used in tandem with soil moisture when needed in the analysis.

The SWAP model is a variably saturated flow model that solves the one-dimensional Richards equation to simulate the soil moisture dynamics in a vertical soil column using a robust implicit finite difference scheme (Belmans et al., 1983). It uses the following Mualem-van Genuchten equations (van Genuchten, 1980; Mualem, 1976) to define the soil hydraulic properties:

$$
\begin{aligned}
& S_{\mathrm{e}}=\frac{\theta(h)-\theta_{\text {res }}}{\theta_{\text {sat }}-\theta_{\text {res }}}=\left(\frac{1}{1+|\alpha h|^{n}}\right)^{m} \\
& K(h)=K_{\text {sat }} S_{\text {e }}^{\lambda}\left[1-\left(1-S_{\mathrm{e}}^{1 / m}\right)^{m}\right]^{2}
\end{aligned}
$$

Equations [1] and [2] require parameters that are soil specific and must be determined beforehand. The parameters of interest for the near-surface soil moisture assimilation study are $\mathbf{k}=\left\{\alpha, n, \theta_{\text {res }}\right.$, $\left.\theta_{\text {sat }}, K_{\text {sat, }} \lambda\right\}$, where $\alpha\left(\mathrm{cm}^{-1}\right)$ is a shape parameter equivalent to the inverse of the bubbling pressure, $n$ (dimensionless) is a shape parameter that accounts for the pore size distribution, $\theta_{\text {res }}\left(\mathrm{m}^{3}\right.$ $\left.\mathrm{m}^{-3}\right)$ and $\theta_{\text {sat }}\left(\mathrm{m}^{3} \mathrm{~m}^{-3}\right)$ are the residual and saturated soil moisture contents, respectively, $K_{\text {sat }}\left(\mathrm{cm} \mathrm{d}^{-1}\right)$ is the saturated hydraulic conductivity, and $\lambda$ (dimensionless) is a shape parameter that accounts for tortuosity in the soil. On average, $\lambda$ is assumed to have a value of 0.5 (Mualem, 1976); van Genuchten (1980) proposed $m$ to be equal to $1-1 / n$. Finally, $S_{\mathrm{e}}$ (dimensionless) in Eq. [2] is the relative saturation and $h$ is the pressure head $(-\mathrm{cm})$.

The SWAP model considers the time-dependent top boundary conditions in terms of either a flux or given head, controlled dynamically based on a given set of nested criteria (Van Dam et al., 1997) related to the atmospheric forcings and hydrologic conditions at the soil surface. The bottom boundary condition can be imposed in various forms (Dirichlet, Neumann, or Cauchy type). The SWAP model is an integrated water management tool containing irrigation and drainage modules as well as process-based crop growth models for simulating the impacts of weather, soil type, plant type, and water management practices on the growth and development of the crops. Detailed descriptions of SWAP can be found in Van Dam et al. (1997) and Van Dam (2000).

To estimate the parameter set $\mathbf{k}$, we combined SWAP with the GA to create a dynamic, inverse, variably saturated flow model. The GA searches for the effective parameter set $\mathbf{k}$, while SWAP tests the proposed parameters by using them in forward simulations. A brief description of the GA search is provided below for completeness. Genetic algorithms are powerful search techniques that combine the survival-of-the-fittest mechanism with a structured yet randomized information exchange to arrive at the search solution (Holland, 1975; Goldberg, 1989). In a binary GA, the search spaces of the unknown parameters (here the soil hydraulic parameters) are discretized into finite lengths and then coded as sets of binary substrings to form a string structure called a chromosome. The bits' arrangement (i.e., 0s and 1s) within a chromosome represents a possible combination of the unknown parameters, which can be a solution to the problem. The procedure starts by randomly generating a set of chromosomes (called a population) serving as starting search positions at the search surface. Since several chromosomes are included within a population, multiple starting points are explored at the start of the search process. The chromosomes are then individually evaluated (in our application, SWAP used each chromosome to simulate the soil moisture dynamics) to determine their suitability based on a given fitness function. The chromosomes then go through the process of selection, crossover, and mutation. Based on their fitness, they compete to be selected, mate, and reproduce for the next generation. During selection, the fitter chromosomes survive and the weaker chromosomes die. The selected chromosomes then randomly mate to exchange genetic information through the process of crossover to produce their offspring. The resulting new chromosomes are subjected to mutation to infuse fresh genetic materials for the new generation and to restore certain genetic characteristics that were lost due to degeneracy. The processes of selection, crossover, and mutation are repeated for many generations until the best possible solution is achieved; this solution is the fittest chromosome that evolved after these many generations.

In this study we used a modified microGA (Carroll, 1998; Ines and Droogers, 2002a; Ines and Honda, 2005) to solve the parameter set $\mathbf{k}$ by minimizing the error between the simulated near-surface soil 
moisture and the measured data for a given day across the simulation period. In the implementation, we determined the parameter subset $\mathbf{p}=\left\{\alpha, n, \theta_{\text {res }}, \theta_{\text {sat }}, K_{\text {sat }}\right\}$ since $\lambda=0.5$ (Mualem,1976), and hence $\mathbf{k}$ $=\{\mathbf{p}, \lambda\}$. The modified microGA is a GA variant that uses a micropopulation to search for the solution of the inverse problem. Aside from restarting the micropopulation, which is a classic feature of the microGA (Krishnakumar, 1989; Goldberg, 2002), we introduced a creep mutation operator (occurring at decimal or real values [base 10]) analogous to the securGA of Carroll (1998) since a jump mutation (occurring at binary values [base 2]) is not allowed in a microGA. We also introduced a time-saving mechanism crucial for coupled methodologies (Ines and Honda, 2005) and an intermittent jump mutation operator to introduce further new genetic materials along the search. The time-saving mechanism allows the GA to remember not only the elite chromosome of the previous generation $(g-1)$ but also the remaining chromosomes so that they will not be evaluated by SWAP if they are reproduced in the next generation $(g)$, but instead will inherit their genetic replicate properties from the previous generation. In the modified microGA, the elite chromosome is always reproduced in the next generation. Moreover, the micropopulation restarts here using a lower degree of bit-positioning similarity (e.g., 90\%) as a basis of population convergence, thereby increasing the restarting occurrence of the micropopulation along the generations (Ines and Droogers, 2002a).

Since we are dealing with real-world conditions, we considered uncertainties in the initial and (bottom) boundary conditions as factors contributing to the parameter uncertainties of the effective modeling domain. We tested two types of bottom boundary conditions: a free-draining soil column and a soil column with variable water table depths. For some test scenarios, we assumed a free-draining soil column (i.e., $\partial h / \partial z=0$ at the bottom boundary, where $z$ is soil depth) with variable initial conditions, namely, wet $[h(z)=-100 \mathrm{~cm}$ at $t=0]$, dry $[h(z)=-500 \mathrm{~cm}$ at $t=0]$, and an equilibrium condition $\left[h(z)=h_{\mathrm{eq}}(z)\right.$ at $\left.t=0\right]$, where $h_{\mathrm{eq}}$ is calculated iteratively using multiple years of simulations. In the case of a water table, we conducted the inverse analyses using three possible groundwater table depths (at 100, 150, or $200 \mathrm{~cm}$ ) as the bottom boundaries, while assuring the initial condition of the soil column to be in equilibrium with the water table. The water table depths were imposed at the start and the end of the simulation period and allowed the model to vary its values during simulations. A soil profile of $2 \mathrm{~m}$ was used in all of the inverse analyses. In some cases, we also explored the effect of uncertainties in the root length and root density on the estimation of effective soil hydraulic parameters.

In addition to the ensemble of simulation conditions as sources of uncertainties, we also used a multipopulation approach in the GA to quantify the uncertainty in the parameter estimates from a search algorithm point of view. The multipopulated modified microGA was applied across the ensemble of simulation conditions analogous to the application of a Monte Carlo simple GA presented by Wu et al. (2006). The multipopulations run in parallel across the ensemble of simulation conditions, but are not designed to interact during the search. After the search is completed, the resulting final populations across the ensemble of simulation conditions are integrated to quantify a relatively robust solution of the inverse problem (Fig. 1). The successful ensemble members that would comprise the final solution are those chromosomes (p) that could satisfy the criterion (i.e., $\mathbf{p}$ fitness should exceed) based on the grand average fitness of the converging solutions across the ensemble of simulation conditions.

Table 1 shows the representations of the soil hydraulic parameters used in the GA. In all GA runs, we used a micropopulation size of 10 , three micropopulations running in parallel, a maximum number of generations of 500, tournament selection, uniform crossover with 0.5 crossover probability, and 0.5 creep mutation probability, while the intermittent jump mutation probability was set to 0.05 occurring at $25,50,75$, and $85 \%$ of the maximum generation. Our initial investigation showed that using more than three micropopulations did not significantly improve the results in terms of estimated parameters and their uncertainty. Thus, we decided to limit our analyses to three micropopulations for all cases.

\section{Field Experiments and Data}

We used measured soil moisture data from three locations in the United States, namely from the Southern Great Plains 1997

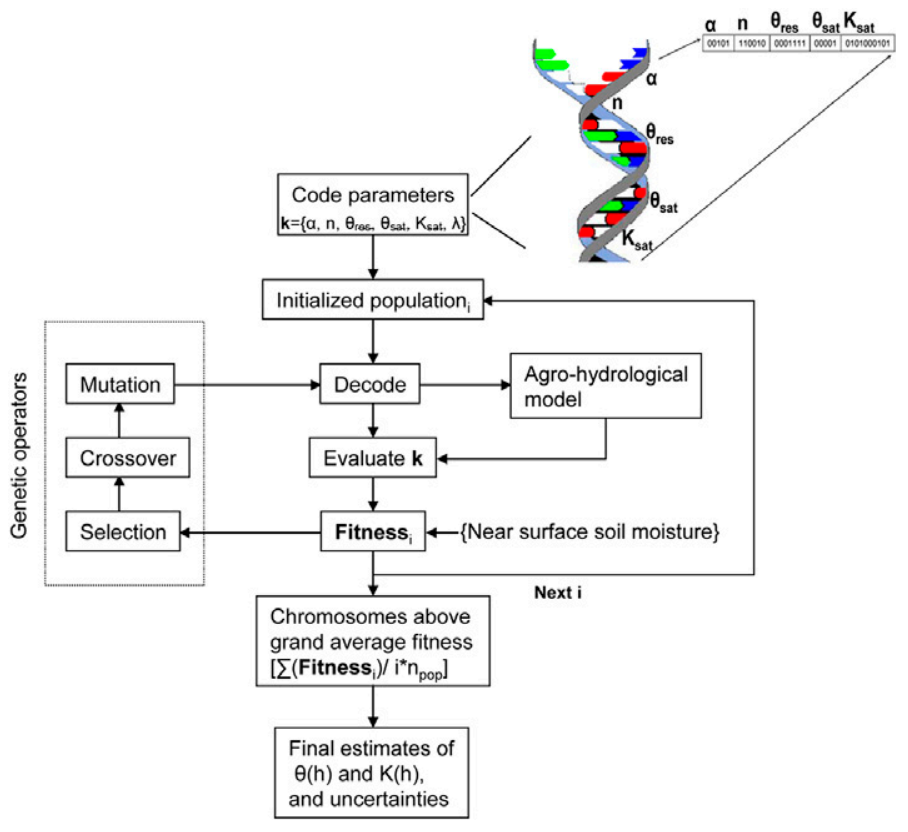

FIG. 1. Conceptual framework of the near-surface soil moisture assimilation ( $\alpha$ is a shape parameter equivalent to the inverse of the bubbling pressure, $n$ is a shape parameter that accounts for the pore size distribution, $\theta_{\text {res }}$ and $\theta_{\text {sat }}$ are the residual and saturated soil moisture content, respectively, $K_{\text {sat }}$ is the saturated hydraulic conductivity, $\lambda$ is a shape parameter that accounts for tortuosity in the soil, $\theta(h)$ is the effective soil water retention, and $K(h)$ is hydraulic conductivity at pressure head $h$.)

TABLE 1. Representations of the Mualem-van Genuchten parameters in the genetic algorithm (GA).

\begin{tabular}{lcccc}
\hline \multirow{2}{*}{ Parameter† } & \multicolumn{2}{c}{ Search space $\neq$} & \multirow{2}{*}{ Bits $(L) \S$} & \multirow{2}{*}{$2^{L}$} \\
\cline { 2 - 3 } & Min. values & Max. values & & no. \\
$\alpha, \mathrm{cm}^{-1}$ & 0.0060 & 0.0330 & 5 & 32 \\
$n$, dimensionless & 1.200 & 1.610 & 6 & 64 \\
$\theta_{\text {res }}, \mathrm{m}^{3} \mathrm{~m}^{-3}$ & $0.061 \pi$ & 0.163 & 7 & 128 \\
$\theta_{\text {sat }}, \mathrm{m}^{3} \mathrm{~m}^{-3}$ & 0.37 & 0.55 & 5 & 32 \\
$K_{\text {sat }}, \mathrm{cm} \mathrm{d}^{-1}$ & 1.84 & 55.7 & 10 & 1024 \\
\hline
\end{tabular}

† $\alpha$ is a shape parameter equivalent to the inverse of the bubbling pressure, $n$ is a shape parameter that accounts for the pore size distribution, $\theta_{\text {res }}$ and $\theta_{\text {sat }}$ are the residual and saturated soil moisture content respectively, $K_{\text {sat }}$ is the saturated hydraulic conductivity.

$\ddagger$ Global search space $=32 \times 64 \times 128 \times 32 \times 1024=8,589,934,592$

$\S$ Example of GA chromosome $\mathbf{p}=\left\{\alpha, n, \theta_{\text {res }}, \theta_{\text {sat }}, K_{\text {sat }}\right\}=\{00101110010$ $0001111000010101000101\}$.

If Minimum values were adjusted based on the minimum soil moisture data in the field. 
(SGP97) hydrology experimental sites in Oklahoma (Heathman et al., 2003, Das and Mohanty, 2006), Soil Moisture Experiment 2002 (SMEX02) sites in Iowa (Jacobs et al., 2004), and soil moisture monitoring sites in Illinois (Hollinger and Isard, 1994; Illinois State Water Survey, 2005) as well as soil moisture data from China (Robock et al., 2000) to validate the inverse modeling-based near-surface soil moisture assimilation scheme.

Figure 2a shows the locations of the selected soil moisture sites (ARS-135, ARS-133, ARS-149, ARS-134, and ARS-159) in the Little Washita watershed in Oklahoma (SGP97). The SGP97 experiment was designed to study the variability of soil moisture within the remote-sensing footprint and to analyze the physical controls of soil moisture dynamics at various spatial scales (from point, to field, to remote-sensing footprint) (Mohanty and Skaggs, 2001). The near-surface and profile soil moisture data used in this study were measured using time domain reflectometry (TDR) probes (Heathman et al., 2003). Daily weather data including solar radiation, precipitation, humidity, minimum and maximum temperature, and wind speed were collected from the USDA-ARS Micronet on-site weather station, while any data gaps were filled by data from nearby Oklahoma Mesonet stations. Table 2 shows the key environmental features of the selected sites. The soils at the study sites ranged from silt loam to sandy loam. In this study, simulations were performed for one calendar year between 1 Jan. and 31 Dec. 1997, in which near-surface soil moisture data (0-5cm depth) during the SGP97 experiment (June-July 1997) were used as conditioning data for the parameter estimation. In the SWAP model, grass was treated as an annual crop with a growth cycle of 1 yr.

The SMEX02 experiment was conducted in Iowa to calibrate and validate the soil moisture measurements of several airborne passive microwave sensors (Jacobs et al., 2004). Soil moisture measurements were conducted in the field during June and July 2002. Figure $2 \mathrm{~b}$ shows the locations of the selected (based on data avail-

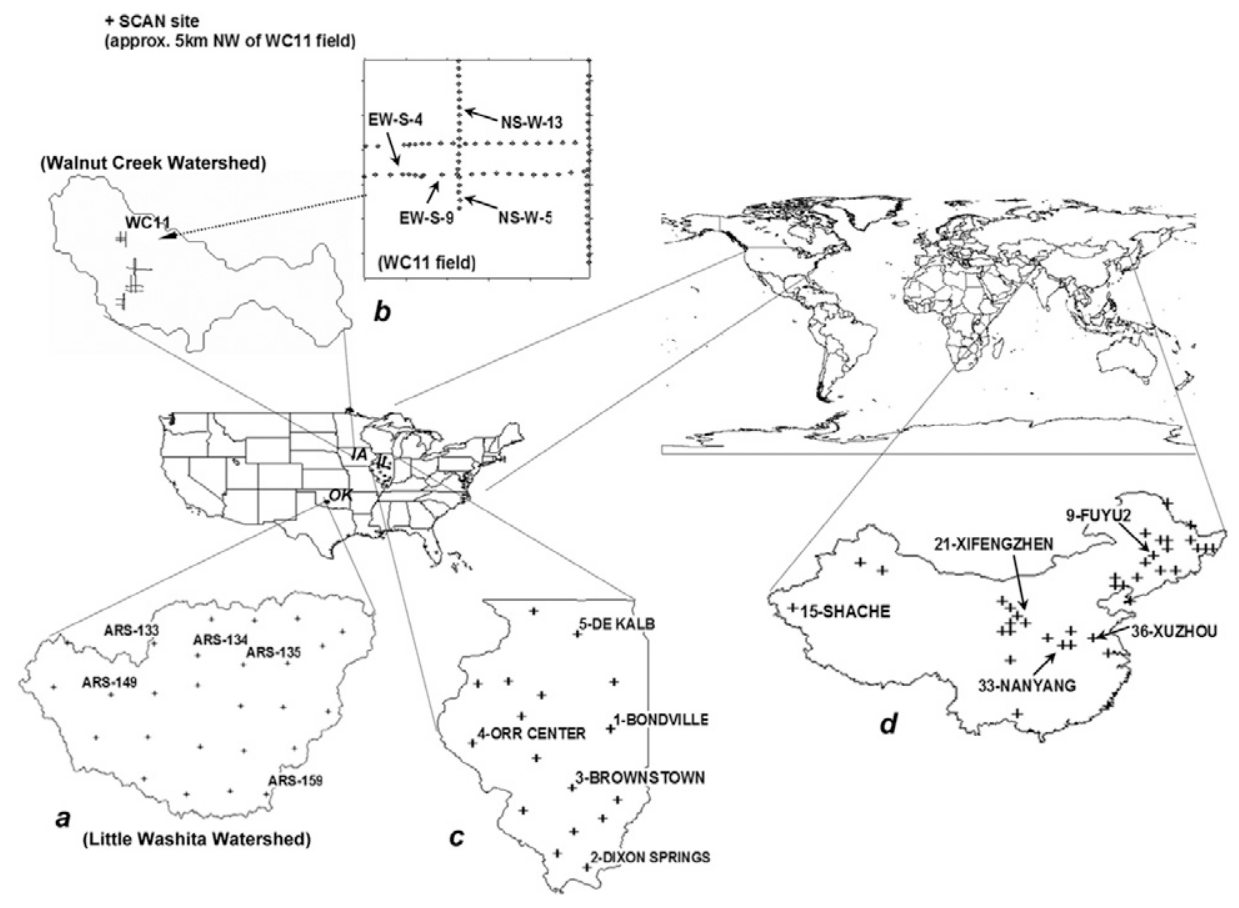

FIG. 2. Locations of (a) Oklahoma Southern Great Plains 1997 (SGP97) sites, (b) lowa Soil Moisture Experiment 2002 (SMEX02) sites, (c) Illinois sites, and (d) China sites. ability) soil moisture measurement sites (NS-W13, NS-W5, EW-S4, and EW-S9) in Field WC11 in the Walnut Creek watershed (see Jacobs et al., 2004, for further details). In addition to the data from the SMEX02 study sites, we also used the Soil Climate Analysis Network (SCAN) site for this field validation because of the large amount of data available from this site. The SCAN site is equipped with an automatic weather station and soil moisture probes up to 1 -m depth that recorded data at hourly or subhourly time steps (Jackson, 2002). Table 2 shows some key features of the SMEX02 and SCAN sites. The soils at the selected sites are predominantly clay loam. The WC11 field was planted with corn (Zea mays L.) and soybean [Glycine max (L.) Merr.] during SMEX02, while the SCAN site was located in a grass area. Simulations for the WC11 sites were made for one cropping season (May-October 2002), while simulations for the SCAN site were performed across the entire year (January-December 2002). The simulation during the winter months (January-April) was used for model spinning. As with the SGP97 sites in Oklahoma, near-surface $(0-$ to $6-\mathrm{cm})$ soil moisture contents measured at the WC11 field sites during the SMEX02 experiment (June-July 2002) and monitored daily near-surface (0to 5-cm) soil moisture (May-October 2002) at the SCAN site were used as conditioning data for the parameter estimation.

Figure 2c shows the selected soil moisture network sites (1-Bondville, 2-Dixon Springs, 3-Brownstown, 4-Orr Center, and 5-De Kalb) in Illinois. These sites were part of a long-term soil monitoring program to study soil climatology in the state of Illinois (Hollinger and Isard, 1994). Soil moisture was measured using TDR probes at various depths down to $2 \mathrm{~m}$ once and twice a month during the noncropping and cropping seasons, respectively. The near-surface soil moisture data considered here was for the 0 - to $10-\mathrm{cm}$ depth. Table 2 shows additional features of the selected sites. Notice that all Illinois sites are grass areas, with predominantly silt loam soils. The simulations were done during January to December 2002.

We also used soil moisture data from the Global Soil Moisture Databank (Robock et al., 2000) for several soil moisture monitoring sites across China for this validation study. Figure $2 \mathrm{~d}$ shows the locations of the selected soil moisture sites (Fuyu2, Shache, Xifengzhen, Nanyang, and Xuzhou) from the large array of soil moisture monitoring sites in China. Soil moisture is measured at a depth of $1 \mathrm{~m}$ with a maximum depth interval of $10 \mathrm{~cm}$ (near the surface) measured on the 8 th, 18th, and 28th day of the month (Li et al., 2005). The selected sites are all unirrigated agricultural areas planted to wheat (Tritucum aestivum L.) and corn (Table 2). Simulations were done during the cropping season of 1992 (May-October) using the available nearsurface soil moisture $(0-10 \mathrm{~cm})$ during the season as conditioning data in the parameter estimation. Daily weather data for the sites were taken from Feng et al. (2004). Important features of the sites are 
listed in Table 2. Note that Site 9 (Fuyu2) was farthest from the weather station.

\section{Validation and Analysis}

We used three different types of data sets to test and validate the results of the inverse modeling experiments, including measured nearsurface and profile soil moisture contents in the field (Heathman et al., 2003; Jacobs et al., 2004; Hollinger and Isard, 1994; Robock et al., 2000; Illinois State Water Survey, 2005), measured soil hydraulic properties measured in the laboratory using soil cores from the experimental fields (Mohanty et al., 2002; Mohanty, unpublished data, 2006), and soil hydraulic properties data of dominant soil textures from the UNSODA database (Leij et al., 1999).

The Pearson's correlation $(R)$ and mean bias error (MBE) of the observed and simulated soil moisture contents were used to assess the performance of the near-surface soil moisture assimilation scheme:

$$
\begin{gathered}
R=\frac{\sum_{t=1}^{n}\left(\hat{\theta}_{\text {pred }, t}-\bar{\theta}_{\text {pred }}\right)\left(\theta_{\text {obs }, t}-\bar{\theta}_{\text {obs }}\right)}{\sqrt{\sum_{t=1}^{n}\left(\hat{\theta}_{\text {pred }, t}-\bar{\theta}_{\text {pred }}\right)^{2} \sum_{t=1}^{n}\left(\theta_{\text {obs }, t}-\bar{\theta}_{\text {obs }}\right)^{2}}} \\
\mathrm{MBE}=\frac{1}{n} \sum_{t=1}^{n}\left(\hat{\theta}_{\text {pred }, t}-\theta_{\text {obs }, t}\right)
\end{gathered}
$$

where $\hat{\theta}_{\text {pred }}$ is the average soil moisture contents (i.e., $\left.1 / m \sum_{i=1}^{m} \theta_{\text {pred, } i}\right)$ of the successful ensemble members $m$ at time $t$ derived from the solutions of GA, $\bar{\theta}_{\text {pred }}$ is the average of $\hat{\theta}_{\text {pred }}, \theta_{\text {obs }}$ is the measured soil moisture content at time $t, \bar{\theta}_{\text {obs }}$ is the average of $\theta_{\mathrm{obs}}$, and $i$ is a running index. Where data were

\begin{tabular}{|c|c|c|c|c|}
\hline Sampling site & $\begin{array}{l}\text { Soil } \\
\text { type }\end{array}$ & $\begin{array}{l}\text { Land } \\
\text { cover }\end{array}$ & $\begin{array}{l}\text { Weather } \\
\text { stationt }\end{array}$ & $\begin{array}{c}\text { Altitude } \\
\text { above mean } \\
\text { sea level }\end{array}$ \\
\hline & & & $\mathrm{km}$ & $\mathrm{m}$ \\
\hline \multicolumn{5}{|c|}{ Southern Great Plains 1997 (SGP97) sites, Oklahomał } \\
\hline ARS-135 (34.93N, -98.02E) & loam & grass & on site & 366 \\
\hline ARS-133 (34.95N, -98.13E) & sandy loam & grass & on site & 430 \\
\hline ARS-149 (34.90N, -98.18E) & silt loam & grass & on site & 420 \\
\hline ARS-134 (34.94N, -98.08E) & loam & grass & on site & 384 \\
\hline ARS-159 (34.80N, -97.99E) & sandy loam & grass & on site & 439 \\
\hline \multicolumn{5}{|c|}{ Soil Moisture Experiment 2002 (SMEX02) sites, lowa§ } \\
\hline SCAN $(42.01 \mathrm{~N},-93.73 \mathrm{E})$ & clay loam & grass & on site & 327 \\
\hline EW-S9 (41.972N, -93.696E) & clay loam & corn & 4.5 & 313 \\
\hline EW-S4 (41.972N, -93.697E) & clay loam & soybean & 4.6 & 325 \\
\hline NS-W5 (41.971N, -93.695E) & clay loam & corn & 4.6 & 313 \\
\hline NS-W13 (41.973N, -93.695E) & $\begin{array}{c}\text { clay loam } \\
\text { Illinois sitesף }\end{array}$ & corn & 4.6 & 313 \\
\hline 1-Bondville (40.05N, -88.22E) & silt loam & grass & near site & 213 \\
\hline 2-Dixon Springs (37.45N, -88.67E) & ) silt loam & grass & near site & 165 \\
\hline 3-Brownstown (38.95N, -88.95E) & silt loam & grass & near site & 177 \\
\hline 4-Orr Center (39.80N, -90.83E) & silt loam & grass & near site & 206 \\
\hline 5-De Kalb (41.85N, -88.85E) & silt loam & grass & near site & 265 \\
\hline \multicolumn{5}{|c|}{ China sites\# } \\
\hline 9-Fuyu2 (45.18N, 124.18E) & loam & corn & 23.77 & 134 \\
\hline 15-Shache (38.43N, 77.27E) & silt clay & wheat & 0.47 & 1231 \\
\hline 21-Xifengzhen (35.73N, 107.63E) & silt clay & wheat & 0.48 & 1421 \\
\hline 33-Nanyang (33.03N, 112.58E) & sand & wheat & 0.48 & 129 \\
\hline 36-Xuzhou (34.27N, 117.28E) & clay loam & wheat & 12.03 & 46 \\
\hline
\end{tabular}

TABLE 2. Key features of the selected sites.

† Proximity to soil sampling sites.

‡ Heathman et al. (2003); Mohanty et al. (2002).

$\S$ Jacobs et al. (2004); Jackson (2002).

II Hollinger and Isard (1994); Illinois State Water Survey (2005)

\# Li et al. (2005); Feng et al. (2004). available, the simulated subsurface soil moisture contents, $\theta(z, t)$, were evaluated against the measured subsurface data.

\section{Results and Discussion}

\section{Southern Great Plains 1997 Sites, Oklahoma}

Fitting Near-Surface Soil Moisture Data

Figure 3 shows an example of a near-surface soil moisture content fitted with the GA for the ARS-135 site within the Little Washita watershed in Oklahoma (Fig. 2a) under a free-draining bottom boundary. The ARS-135 site consists of mostly loam soils, which are expected to be highly identifiable by inverse modeling (Jhorar et al., 2002, 2004; Van Dam, 2000). Apparently, the observed near-surface soil moisture content closely matched the simulated values $\left(R=0.90 ; \mathrm{MBE}=-0.002 \mathrm{~cm}^{3} \mathrm{~cm}^{-3}\right)$ using GA-derived $\theta(h)$ and $K(h)$ as inputs in the forward simulations. This result suggests that the GA generated a soil hydraulic parameter set $\mathbf{p}$ capable of reproducing the soil moisture dynamics of the near-surface soil layer of the field study site. The spread in the simulated near-surface soil moisture contents also appears to be narrow, suggesting that the simulated soil moisture contents among the successful ensemble members are identical.

Effects of Initial and Bottom Boundary Conditions and Rooting Depth and Density on Soil Hydraulic Properties

Modeling soil moisture in actual field conditions is more complex than for studies conducted under controlled environments (Abbaspour et al., 2000). Hence, we conducted exploratory simulations to better understand the involved soil hydrologic processes and to better characterize the effective modeling domain for the inverse analysis. We used, for this purpose, several soil moisture sampling sites in the Little Washita watershed to explore the sensitivity of the inverse modeling-based near-surface soil moisture assimilation scheme subject to possible sources of uncertainties often encountered in the field. Modeling soil moisture under field conditions involves uncertainties associated with the selection of the initial and boundary conditions, vegetation parameters, soil moisture measurements, soil hydraulic properties,

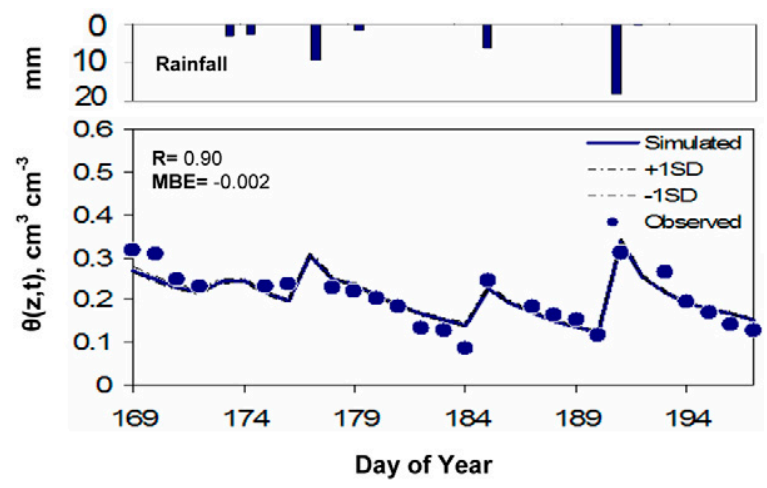

FIG. 3. Rainfall (top panel) and observed and simulated near-surface (depth $z=0-5 \mathrm{~cm}$ ) soil moisture $[\theta(z, t)]$ with derived effective soil water retention $\theta(h)$ and hydraulic conductivity $K(h)$ for Oklahoma Southern Great Plains 1997 (SGP97) Site ARS-135 in 1997; bottom boundary condition is free drainage [i.e., $\partial(h+z) / \partial z=1]$; $\mathrm{MBE}$ is mean bias error. 
and other ancillary data (e.g., weather), as well as uncertainties about the governing soil water flow model itself to be used in the modeling effort. These uncertainties may affect the parameter estimation process and perhaps the derived soil hydraulic parameters (Kool and Parker, 1988; Ines and Droogers, 2002a). In this study, we explored combinations of initial and bottom boundary conditions, rooting depth, and root density as sources of uncertainties in the soil hydraulic parameter estimation.

Figure 4 shows the effects of the initial and bottom boundary conditions (Fig. 4a, 4b, 4e, and 4f), rooting depth (Fig. 4b, 4c, 4g, and 4f), root density (Fig. 4b, 4d, 4f, and 4h), and the combination of rooting depth and root density (Fig. 4c, 4d, 4g, and 4h) on the estimated $\theta(h)$ and $K(b)$ functions for the ARS-135 site in the Little Washita watershed. We found almost no significant effects of the varying conditions (applied to the modeling domain) in the estimation of $\theta(h)$ and $K(h)$ at ARS-135. Only a slight change in the drier and wetter ends of $\theta(b)$ was observed when the initial and bottom boundary conditions were changed (Fig. $4 \mathrm{a}$ and $4 \mathrm{~b}$ ). This trend occurred with changing root density (Fig. 4b and 4d) and rooting depth (Fig. 4b and 4c). A slight change in the drier end of $\theta(b)$ was obtained when both the rooting depth and density were changed (Fig. 4c and 4d). Interestingly, only the uncertainty bounds of the estimated $K(b)$ appeared to be affected by the changes in the modeling domain, while the mean $K_{\text {sat }}$ derived by the parameter estimation did not change significantly (Fig. 4e-4h). We should note, however, that these results may be unique for this soil type (ARS-135, a loam) and the conditions used in the simulations. The results from other SGP97 experimental sites (e.g., ARS-133, a sandy loam, results not shown here) indicated that the $K(h)$ estimates could be sensitive to the rooting depth and root density variations, while the estimates of $\theta(h)$ did not vary significantly.

We validated the estimated soil hydraulic parameters of ARS135 and other SGP97 sites using independently derived $\theta(b)$ and $K_{\text {sat }}$ data from laboratory measurements (Mohanty et al., 2002) and
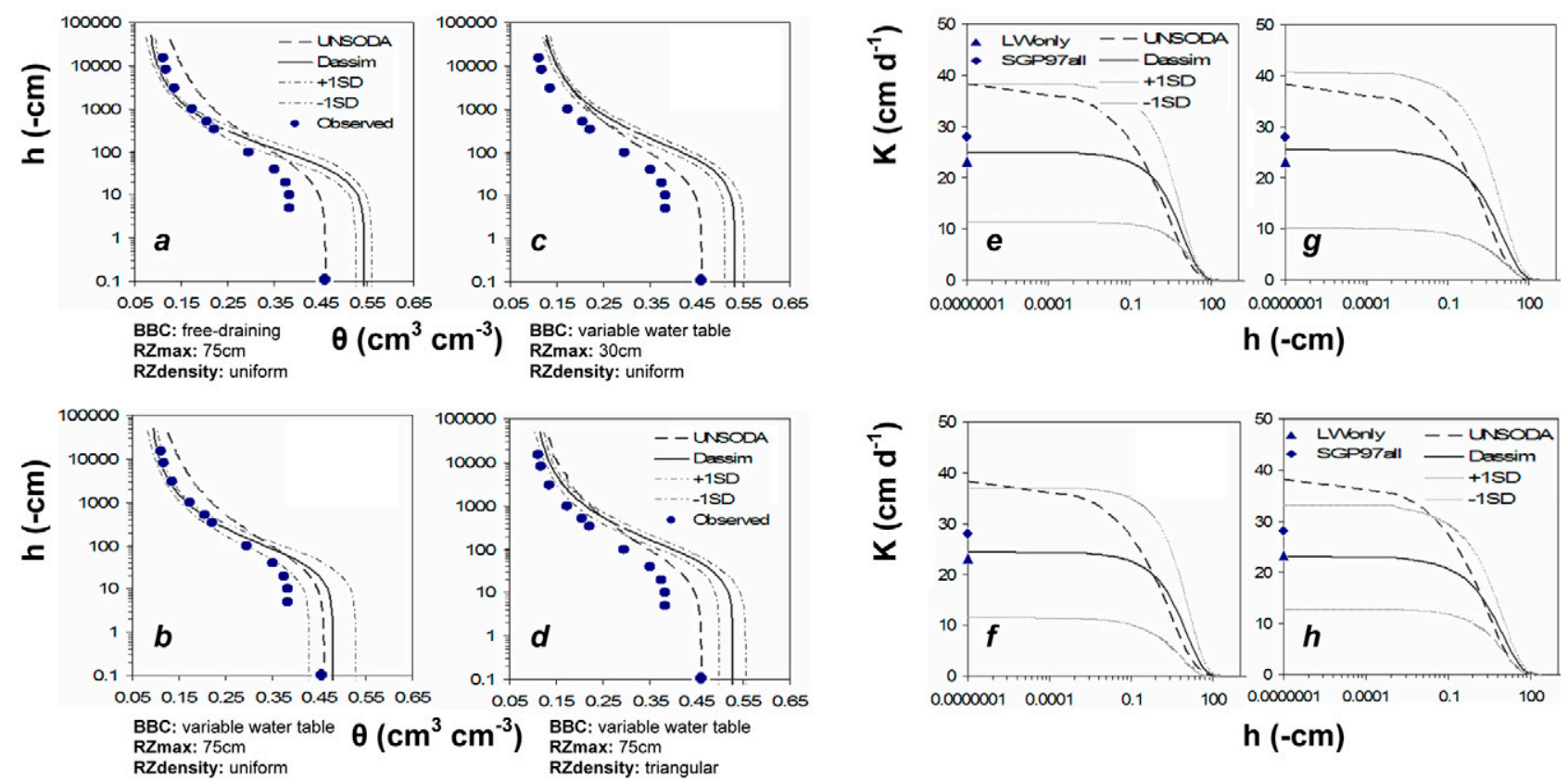

FIG. 4. Effects of ( $a, b, e$, and f) initial and bottom boundary conditions, (b, c, g, and f) rooting depth, and (b, d, f, and h) root density on effective water retention $\theta(h)$ and hydraulic conductivity $K(h)$ for the Oklahoma Southern Great Plains 1997 (SGP97) Site ARS-135 for a loam soil (BBC is bottom boundary condition, RZmax is maximum rooting depth, RZdensity is root density, and Dassim denotes predicted by the inverse modelingbased near-surface soil moisture assimilation scheme).

from the soil hydraulic database UNSODA (Leij et al., 1999). Since we did not use any macroporosity in the soil hydraulic model, we only considered the $K_{\text {sat }}$ values from the Mohanty et al. (2002) data sets that were $<200 \mathrm{~cm} \mathrm{~d}^{-1}$ when calculating the validation average $K_{\text {sat }}$ value for a particular soil type. The SGP97all and LWonly symbols in Fig. 4e to $4 \mathrm{~h}$ indicate the average $K_{\text {sat }}$ of, in this case, the loam soil for all the SGP97 experimental sites $(S D=32.9 \mathrm{~cm}$ $\left.\mathrm{d}^{-1}\right)$ and the Little Washita watershed only $\left(\mathrm{SD}=30.2 \mathrm{~cm} \mathrm{~d}^{-1}\right)$, respectively. They are captured well by the $K(h)$ estimates of the GA. The estimates for $\theta(h)$ were also found to be reasonable in the drier range of the measured soil hydraulic data (Fig. 4a-4d). The wetter range, however, appeared to be overestimated. Note here that the measured $\theta(\mathrm{h})$ data were not used as conditioning data in the parameter estimation. We only used the observed near-surface soil moisture content to estimate the effective $\theta(b)$ and $K(h)$ of the modeling domain. A probable reason for the overestimation of $\theta_{\text {sat }}$ is the limited information (data range) contained within the time series of the observed near-surface soil moisture data. The measured highest near-surface soil moisture content at the ARS-135 site during the SGP97 campaign was about $0.31 \mathrm{~m}^{3} \mathrm{~m}^{-3}$ (see Fig. 3). The GA cannot specify the "true" value of $\theta_{\text {sat }}$ since the information content of the data does not allow the algorithm to do so. The sensitivity of $\theta_{\text {sat }}$ to the search and fitness function used in the GA cannot be ruled out, however, as an integral factor for this overestimation.

With respect to the UNSODA data, a fairly good agreement was obtained with the laboratory-measured $\theta(h)$ values, although a bias between them is apparent (Fig. $4 \mathrm{a}-4 \mathrm{~d}$ ). This is expected since the UNSODA data were derived from the average values of a range of soils for a particular textural class (Leij et al., 1999). It is interesting to note that the GA-estimated $\theta(b)$ function followed the drier end of the laboratory-derived $\theta(h)$ values more closely. The estimated $K(h)$ from the GA also closely captured the mean $K_{\text {sat }}$ values measured in the laboratory, while the UNSODA data matched somewhat fairly (Fig. 4e- $4 \mathrm{~h})$. The drier end of the estimated $K(h)$, however, matched

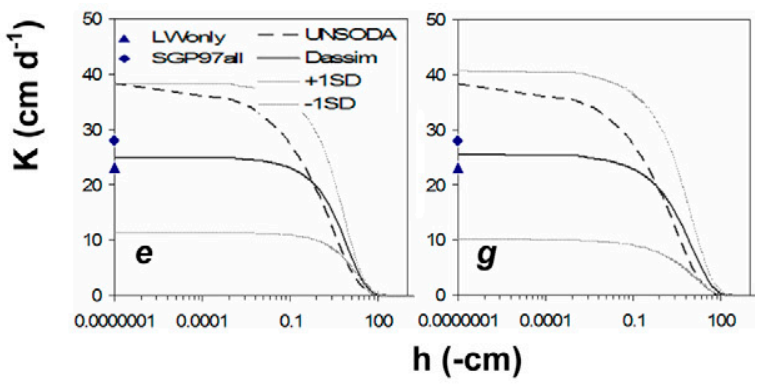

www.vadosezonejournal.org · Vol. 7, No. 1, February 2008 
the UNSODA data quite well. These comparisons suggest that the inverse parameter estimation by the GA provides robust results and can be used to indirectly estimate the hydraulic properties of the soil. Aside from saving time and money from tedious laboratory analysis, the GA approach can be applied at larger scales, thus allowing a regional estimation of effective soil hydraulic parameters crucial for hydroclimatic modeling. Sources of uncertainties under actual field conditions can be also incorporated in the soil hydraulic parameter estimation process using the GA scheme.

Effects of Initial and Bottom Boundary Conditions and Rooting Depth and Density on Profile Soil Moisture Dynamics

Figure 5 shows the effects of the initial and bottom boundary conditions (Fig. 5a and 5b), rooting depth (Fig. 5b and 5c), and root density (Fig. $5 \mathrm{~b}$ and $5 \mathrm{~d}$ ) on $\theta(z, t)$ for $z=0$ to $60 \mathrm{~cm}$. Obviously, with varied conditions in the modeling domain, the simulated subsurface $(0-60-\mathrm{cm})$ soil moisture contents are quite different from each set of simulated conditions (Fig. 5a-5d). This result was expected since the flow regimes are quite different under different initial and boundary conditions, even with more or less similar $\theta(h)$ and $K(h)$ values used in the simulations (Fig. 4a-4h).

The case of a free-draining soil column with uniform root denobserved near-surface $(0-5-\mathrm{cm})$ water contents matched reasonably well (Fig. 3), the observed and simulated subsurface (0-60-cm) soil moisture contents showed some difference. Similar results were observed by Heathman et al. (2003) in their direct-insertion data assimilation study. They concluded that the influence of near-surface information could be limited only to the approximately top $30 \mathrm{~cm}$ of the soil. Capehart and Carlson (1997) also observed a decoupling of surface and root-zone soil moisture. They suggested that near-surface soil moisture derived from remote sensing is probably not even useful for deriving the column-average soil moisture. Our earlier numerical studies showed, however, that the relationship between near-surface and subsurface $(50-60-\mathrm{cm})$ soil moisture is relatively strong, espesity needs further examination (Fig. 5a). While the simulated and

cially in a wet year (not shown). During a dry year, this relationship between the near-surface and subsurface diminishes, but a signal could be still observed. Based on these findings, we suggest that as long as the modeling domain is represented well, it is potentially possible to estimate the effective soil hydraulic properties and the soil moisture dynamics of the subsurface using mainly near-surface soil moisture information in the inverse modeling process.

In this study, we hypothesized that the modeling domain may not be well represented using a free-draining assumption. A freedraining condition at the bottom boundary has a unit hydraulic gradient, as such will exclude the effect of a perched or shallow water table that may be present in the subsurface due to a lowconductive layer underneath. Abbaspour et al. (2000) succeeded in matching the soil moisture and pressure head distributions of their field sites only after they considered a better representation of their hydrologic domain. Figure $5 \mathrm{~b}$ shows simulated subsurface soil moisture with variable water table depths as bottom boundaries. An improvement in the simulated soil moisture is observed, although the effect of a deep rooting system $(75 \mathrm{~cm})$ with uniform root density is apparent. Reducing the rooting depth to $30 \mathrm{~cm}$ did improve the simulation further (Fig. 5c); however, field measurements showed that the vegetation at the sampling sites consisted of tall grasses with relatively deep roots (Mohanty et al., 2002). Figure $5 \mathrm{~d}$ shows the results of a relatively deep-rooted system with a triangular root density configuration. Under more appropriate bottom boundary conditions, rooting depth, and root distribution, the simulated subsurface soil moisture had improved significantly (Fig. $5 \mathrm{~d}$; higher $R$, lower MBE). Hence, we adopted this modeling domain for the rest of the SGP97 study (Oklahoma), the SMEX02 sites (Iowa), the Illinois sites, and the China sites.

Soil Hydraulic Properties and Soil Moisture Dynamics at the Other Oklahoma Sites

Figure 6 also shows the derived $\theta(h)$ and $K(h)$ functions by using the GA for the other SGP97 sites in Oklahoma (see Fig.
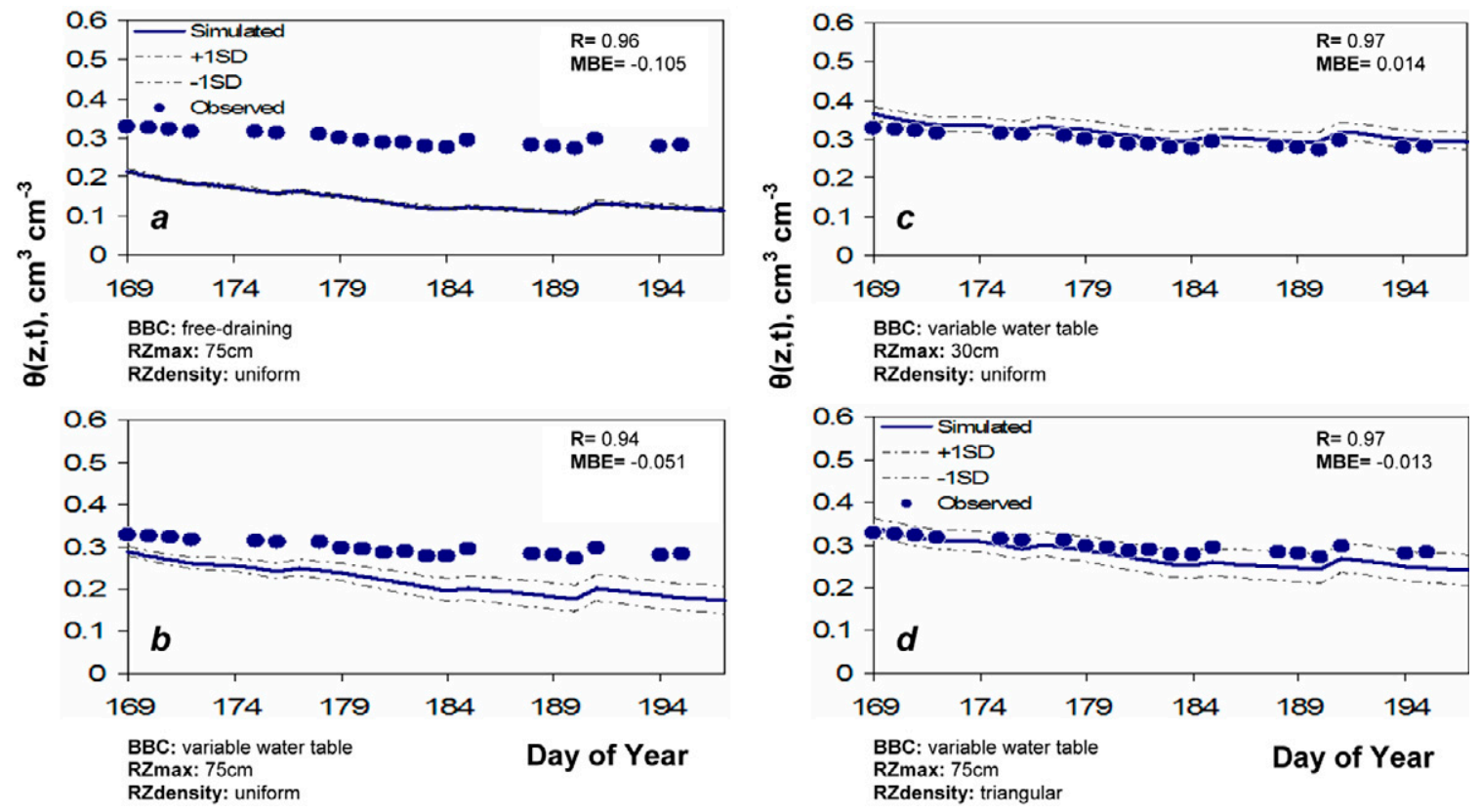

FIG. 5. Effects of ( $a$ and $b$ ) initial and bottom boundary conditions, ( $b$ and $c$ ) rooting depth, and (b and d) root density on subsurface $(z=0-60 \mathrm{~cm})$ soil moisture $\theta(z, t)$ for the Oklahoma Southern Great Plains 1997 (SGP97) Site ARS-135 for a loam soil in 1997 (BBC is bottom boundary condition, RZmax is maximum rooting depth, RZdensity is root density). 2a), namely ARS133 (sandy loam), ARS-149 (silt (loam), and ARS159 (sandy loam). The ARS-134 and ARS-159 sites were used as replicates for the ARS-135 (loam) and ARS133 (sandy loam) sites, respectively, to cross-validate the results from the same soil textural class. We hypothesize that soils with similar textural class should behave similarly as long as there are no significant structural components (e.g., loam), ARS-134 
macropores) affecting their hydraulic properties. Figure 7 also shows the simulated near-surface $(0-$ to $5-\mathrm{cm})$ and subsurface (0- to $60-\mathrm{cm})$ soil moisture using the GA-derived $\theta(b)$ and $K(b)$ (Fig. 6) as inputs in the forward simulations.

The estimated $\theta(h)$ at the ARS-133 site appears to correspond well with the measured $\theta(b)$ data (Fig. 6a); however, the estimated $\theta(h)$ at ARS-159 site, which has a texture similar to ARS-133, did not correspond well with the measured data (Fig. 6d). In the drier range, the estimated $\theta(h)$ overshot the measured $\theta(h)$. This overshooting of $\theta(h)$ at the ARS-159 site could be attributed to the information content of the measured near-surface soil moisture used as conditioning data in the parameter estimation (Fig. $7 \mathrm{~d}$ ). Also, measurement and calibration errors of the field and laboratory data cannot be discounted as factors affecting the result. An important point to consider here is that while ARS-133 and ARS-159 are both sandy loam sites, their measured $\theta(b)$ values from the laboratory analysis were not exactly the same. On the other hand, the GA-estimated $\theta(h)$ values for both sites appear to agree better, which supports our initial hypothesis that soils with similar textural class could behave similarly.

The GA-estimated $\theta(h)$ for the ARS-134 (loam) site appears to be in good agreement with observations in the drier end of the soil water retention curve (Fig. 6c). We did not have measured $\theta(h)$ data for the ARS-149 (silt loam) site, but using measured $\theta(b)$ data from a nearby sampling site and from the UNSODA database, the estimated soil water retention property $\theta(h)$ faired well (Fig. 6b). Moreover, it is apparent that the estimated $K(h)$ is more variable (with large uncertainty bounds, Fig. 6e-6h) compared with $\theta(h)$ for a variety of soils. Generally, however, despite the above mentioned discrepancies, the GA-estimated $\theta(h)$ and $K(h)$ functions were fairly representative of the effective modeling domains studied. The MBE and $R$ values of the simulated and observed subsurface soil moisture (see Fig. 7, bottom panels) ranged from -0.035 to $0.067 \mathrm{~m}^{3} \mathrm{~m}^{-3}$ and 0.83 to 0.94 , respectively.
A summary of derived soil hydraulic parameters using the inverse modeling-based near-surface soil moisture assimilation scheme for the selected SGP97 sites in Little Washita watershed, Okalahoma, is given in Table 3. The results were derived using variable water table depths at the bottom boundaries and a $75-\mathrm{cm}$ rooting depth with a triangular root density distribution.

Soil Moisture Experiment 2002 Sites, lowa

\section{Soil Climate Analysis Network Site}

The SCAN site is located in Ames, IA, $5 \mathrm{~km}$ northwest of the SMEX02 Walnut Creek watershed field WC11 site (Fig. 2b). We also used variable water table depths as bottom boundary conditions in the near-surface soil moisture assimilation scheme for the SMEX02-SCAN site. Figure 8 shows the results of the nearsurface soil moisture assimilation using the GA-derived $\theta(h)$ and $K(b)$ values (Table 4 ) in the forward simulations. The $R$ and $\mathrm{MBE}$ values of the observed and simulated near-surface soil moisture appear to be less than those for SGP97. Despite the large amount of available soil moisture data used in the parameter estimation, the near-surface soil moisture was only fairly predicted. It appears that the rainfall event $(\sim 23 \mathrm{~mm})$ during DOY (Day of the Year) 185 (Fig. 8, top panel) did not immediately change the soil moisture dynamics at the 0 - to 5-cm depth (Fig. 8a). Similar delays in the near-surface soil moisture dynamics were observed on DOY 206 to 208 rainfall events $(\sim 10 \mathrm{~mm})$. This is one limitation of the soil-water flow model used, which operates on a daily time step and hence cannot account for subdaily variability of the soil moisture dynamics and the time mismatch between soil moisture sampling and rainfall occurrence on a particular day.

No laboratory-measured $\theta(h)$ data were available for the SCAN site to evaluate the GA-derived $\theta(b)$, but using the data for a clay loam soil from the UNSODA database, we found that the drier end of the estimated $\theta(b)$ was well defined, while $\theta_{\text {sat }}$ was
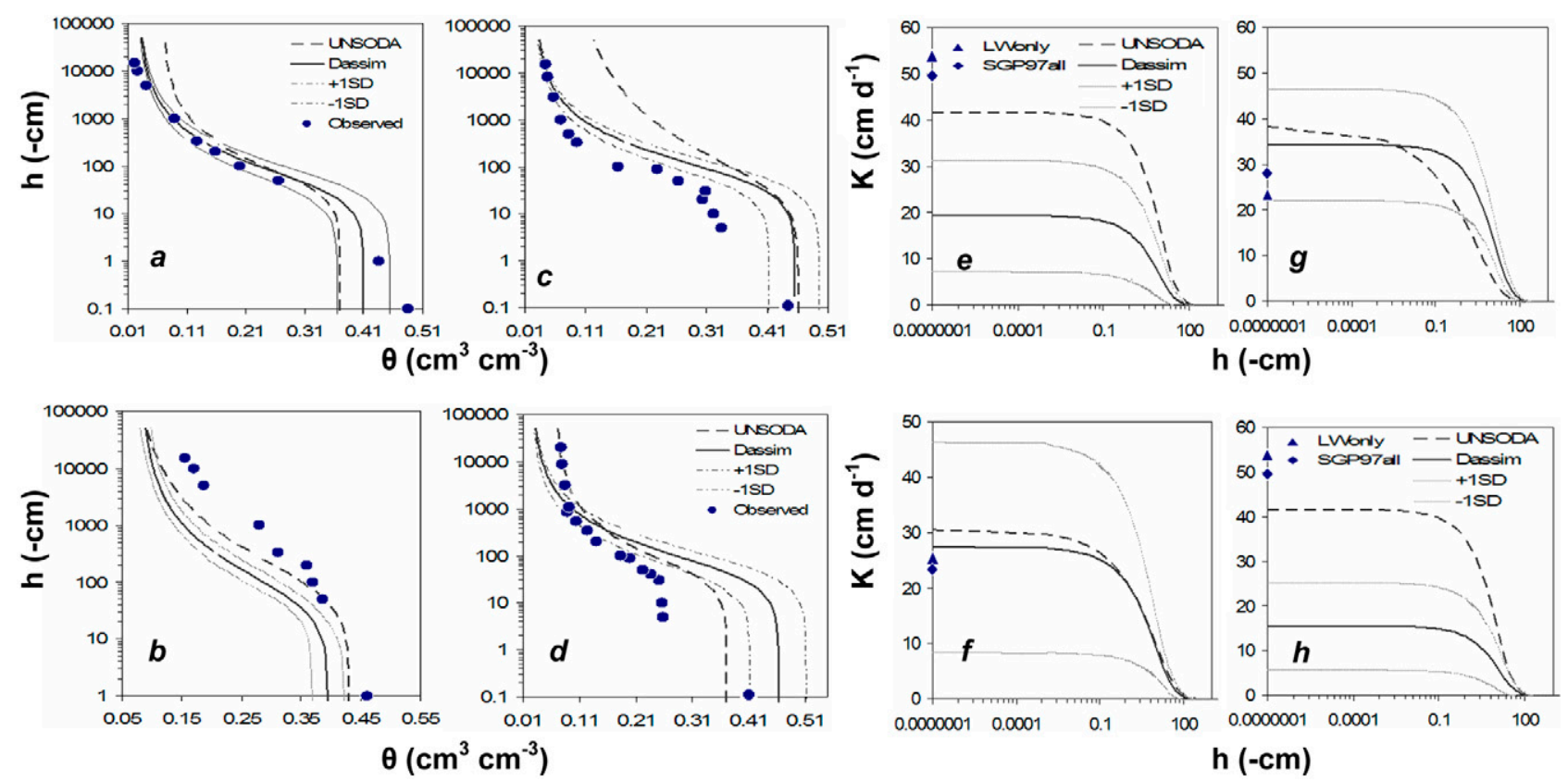

FIG. 6. Derived effective water retention $\theta(h)$ and hydraulic conductivity $K(h)$ for Oklahoma Southern Great Plains 1997 (SPG97) sampling sites: (a and e) ARS-133, (b and f) ARS-149, ( $c$ and $g$ ) ARS-134, and ( $d$ and $h$ ) ARS-159. Bottom boundary condition is a variable water table; maximum rooting depth is $75 \mathrm{~cm}$; root density is triangular; Dassim denotes predicted by the inverse modeling-based near-surface soil moisture assimilation scheme. 
underestimated (Fig. 8c). This underestimation was reflected in the simulated subsurface soil moisture (high negative MBE; Fig. $8 \mathrm{~b})$. Figure $8 \mathrm{~d}$ shows a fair estimate of $K(h)$ for a clay loam soil based on the UNSODA data.

Soil Hydraulic Properties and Soil Moisture Dynamics at the Other lowa Sites

Figure 9 shows a comparison between the laboratory-measured $\theta(h)$ and GA-derived $\theta(h)$ functions (Table 4) at the four SMEX02 sampling sites in the Walnut Creek watershed, Iowa (Fig. 2b). The number of observations and range of near-surface
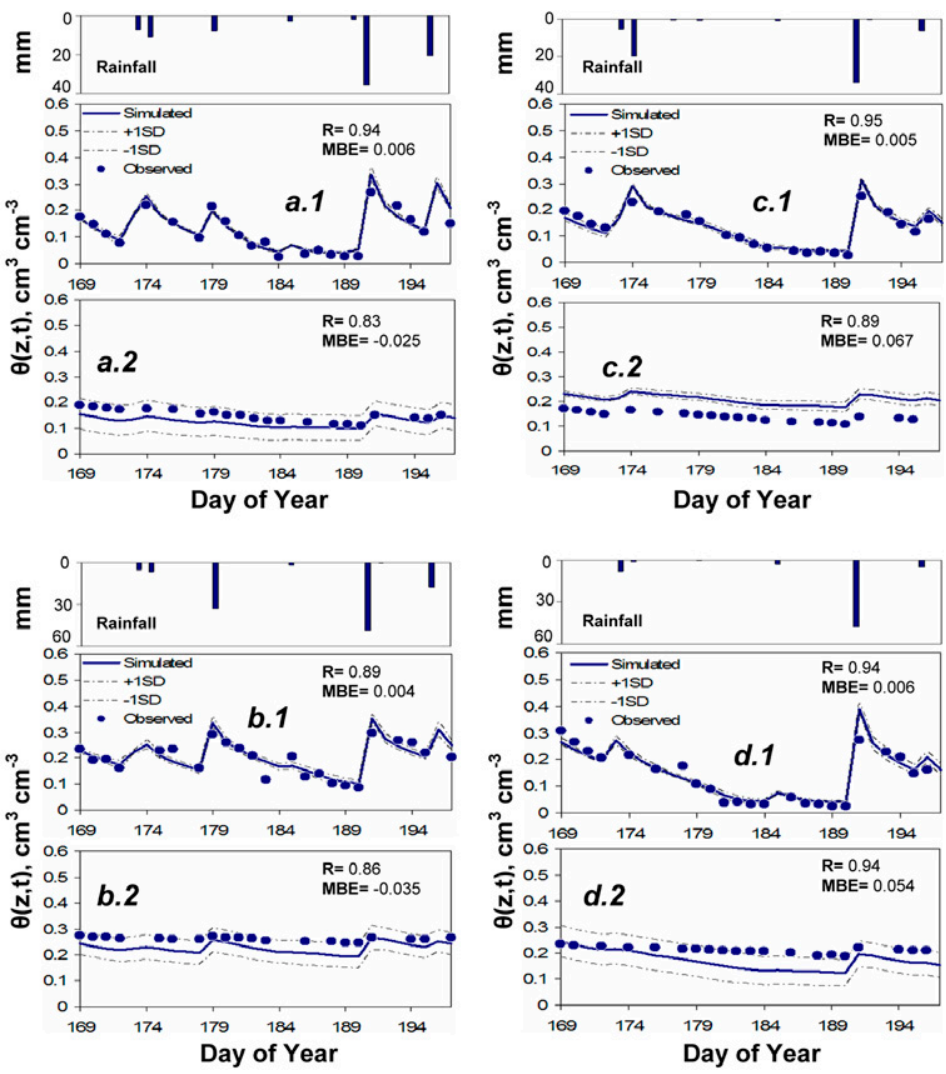

FIG. 7. Rainfall (top panels), observed and simulated soil moisture $\theta(z, t)$ at the near-surface $(z=0-5 \mathrm{~cm})$ (middle panels), and subsurface $(z=0-60 \mathrm{~cm})$ (bottom panels) for Oklahoma Southern Great Plains 1997 (SGP97) sites in 1997: (a) ARS-133, (b) ARS-149, (c) ARS-134, and (d) ARS-159. Bottom boundary condition is a variable water table; maximum rooting depth is $75 \mathrm{~cm}$; root density is triangular.

TABLE 3. Derived soil hydraulic parameters $†$ for the selected Southern Great Plains 1997 (SGP97) sites, Oklahoma.

\begin{tabular}{|c|c|c|c|c|c|c|}
\hline Site & Statistic & $\alpha$ & $n$ & $\theta_{\text {res }}$ & $\theta_{\text {sat }}$ & $K_{\text {sat }}$ \\
\hline & & $\mathrm{cm}^{-1}$ & & $-\mathrm{m}$ & -3 & $\mathrm{~cm} \mathrm{~d}^{-1}$ \\
\hline \multirow[t]{2}{*}{ ARS-135 } & Mean & 0.016 & 1.491 & 0.097 & 0.527 & 23.1 \\
\hline & SD & 0.005 & 0.067 & 0.016 & 0.029 & 10.2 \\
\hline \multirow[t]{2}{*}{ ARS-133 } & Mean & 0.028 & 1.570 & 0.027 & 0.410 & 19.3 \\
\hline & SD & 0.005 & 0.034 & 0.001 & 0.044 & 12.0 \\
\hline \multirow[t]{2}{*}{ ARS-149 } & Mean & 0.020 & 1.511 & 0.078 & 0.394 & 27.4 \\
\hline & SD & 0.008 & 0.084 & 0.012 & 0.027 & 19.0 \\
\hline \multirow[t]{2}{*}{ ARS-134 } & Mean & 0.018 & 1.602 & 0.027 & 0.454 & 34.3 \\
\hline & SD & 0.005 & 0.008 & 0.001 & 0.041 & 12.2 \\
\hline \multirow[t]{2}{*}{ ARS-159 } & Mean & 0.022 & 1.605 & 0.027 & 0.462 & 15.6 \\
\hline & SD & 0.007 & 0.008 & 0.001 & 0.050 & 9.8 \\
\hline
\end{tabular}

$\dagger \alpha$ is a shape parameter equivalent to the inverse of the bubbling pressure, $n$ is a shape parameter that accounts for the pore size distribution, $\theta_{\text {res }}$ and $\theta_{\text {sat }}$ are the residual and saturated soil moisture content respectively, $K_{\text {sat }}$ is the saturated hydraulic conductivity. soil moisture data during the SMEX02 experiment are somewhat limited (Fig. 10). The inverse modeling results (Fig. 9) showed good agreement between the measured and derived $\theta(b)$ for Site EW-S9 and fair agreement for Sites NS-W5 and NS-W13. It is interesting to note that the GA-derived $\theta(h)$ values agreed better with the measured data than the more generalized UNSODA data. Since Field WC11 is an agricultural field, using actual field data to estimate the soil hydraulic properties better accounted for the impacts of tillage and other agricultural practices on the estimated values. Moreover, the deviation of the estimated and the measured values at the drier end of the soil water retention curve at Site EW-S4 could be attributed to the narrow range of the near-surface soil moisture data used in the parameter estimation. The mismatch in the timing of rainfall and the near-surface soil moisture measurements and spatial variation in precipitation affecting the soil hydraulic parameter estimation are also apparent (Fig. 10). Weather data from the SCAN site were used in the parameter estimation (Table 2, Fig. 2b). At the SMEX02 sites, however, the high $R(0.75-0.98)$ and small MBE ( -0.011 to $-0.003 \mathrm{~m}^{3} \mathrm{~m}^{-3}$ ) between the observed and simulated near-surface soil moisture reflected the general success of the near-surface soil moisture assimilation scheme. No comparisons are shown for the subsurface soil moisture

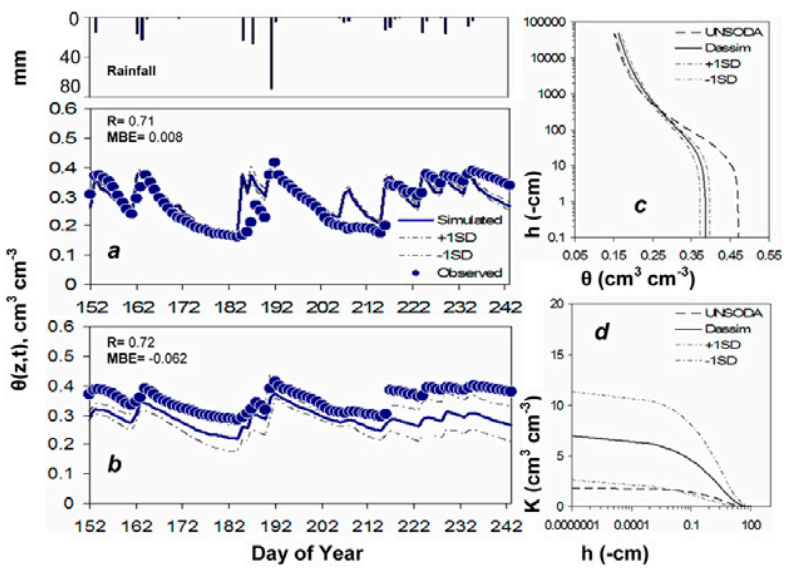

FIG. 8. Rainfall (top left), observed and simulated soil moisture $\theta(z, t)$ at $(a)$ near surface $(z=0-5 \mathrm{~cm})$ and $(b)$ subsurface $(z=$ $0-50 \mathrm{~cm}$ ) using (c and d) the derived effective water retention $\theta(h)$ and hydraulic conductivity $K(h)$ for the lowa Soil Moisture Experiment 2002 (SMEX02) site Soil Climate Analysis Network (SCAN) in 2002.

TABLE 4. Derived soil hydraulic parameters $†$ for the selected Soil Moisture Experiment 2002 (SMEX02) sites, lowa.

\begin{tabular}{|c|c|c|c|c|c|c|}
\hline Site & Statistic & $\alpha$ & $n$ & $\theta_{\text {res }}$ & $\theta_{\text {sat }}$ & $K_{\text {sat }}$ \\
\hline & & $\mathrm{cm}^{-1}$ & & $-m$ & -3 & $\mathrm{~cm} \mathrm{~d}^{-1}$ \\
\hline \multirow[t]{2}{*}{ SCAN } & Mean & 0.028 & 1.256 & 0.118 & 0.386 & 7.0 \\
\hline & SD & 0.005 & 0.050 & 0.011 & 0.012 & 4.4 \\
\hline \multirow[t]{2}{*}{ EW-S9 } & Mean & 0.019 & 1.580 & 0.062 & 0.373 & 1.9 \\
\hline & SD & 0.002 & 0.021 & 0.002 & 0.004 & 0.1 \\
\hline \multirow[t]{2}{*}{ EW-S4 } & Mean & 0.018 & 1.276 & 0.150 & 0.373 & 36.1 \\
\hline & SD & 0.007 & 0.059 & 0.025 & 0.004 & 17.6 \\
\hline \multirow[t]{2}{*}{ NS-W5 } & Mean & 0.023 & 1.582 & 0.062 & 0.373 & 2.6 \\
\hline & SD & 0.002 & 0.046 & 0.001 & 0.003 & 0.8 \\
\hline \multirow[t]{2}{*}{ NS-W13 } & Mean & 0.032 & 1.518 & 0.118 & 0.383 & 2.6 \\
\hline & SD & 0.001 & 0.083 & 0.007 & 0.004 & 0.6 \\
\hline
\end{tabular}

$\dagger \alpha$ is a shape parameter equivalent to the inverse of the bubbling pressure, $n$ is a shape parameter that accounts for the pore size distribution, $\theta_{\text {res }}$ and $\theta_{\text {sat }}$ are the residual and saturated soil moisture content respectively, $K_{\text {sat }}$ is the saturated hydraulic conductivity. 

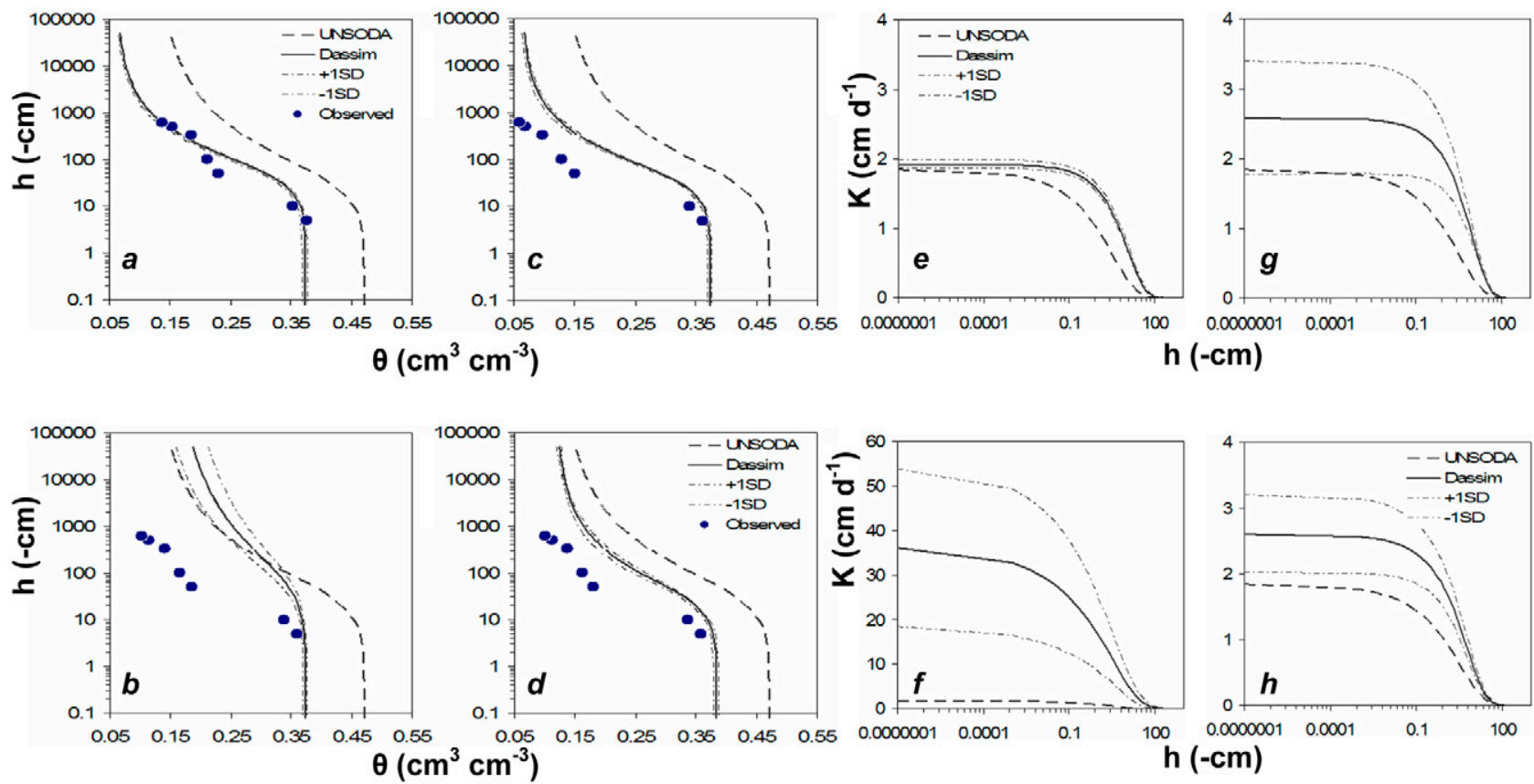

FIG. 9. Derived effective water retention $\theta(h)$ and hydraulic conductivity $K(h)$ for the lowa Soil Moisture Experiment 2002 (SMEX02) sampling sites: (a and e) EW-S9, (b and f) EW-S4, (c and g) NS-W5, and ( $d$ and h) NS-W13. Dassim denotes predicted by the inverse modeling-based near-surface soil moisture assimilation scheme.
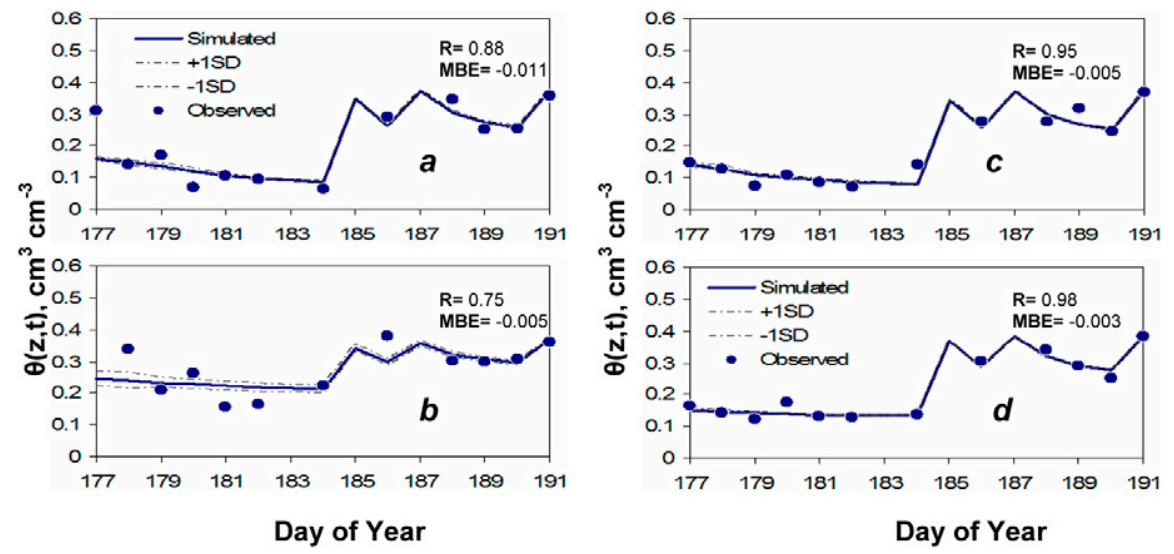

FIG. 10. Observed and simulated near-surface $(z=0-6 \mathrm{~cm})$ soil moisture $\theta(z, t)$ for the lowa Soil Moisture Experiment 2002 (SMEX02) sampling sites in 2002: (a) EW-S9, (b) EW-S4, (c) NS-W5, and (d) NS-W13. MBE is mean bias error.

since there were no subsurface measurements available for these sites. The majority of estimated $K(h)$ and $K_{\text {sat }}$ values (Fig. 9e-9h, Table 4) for Sites EW-S9, NS-W5, and NS-W13 are fairly good estimates of a clay loam soil (matrix) based on the UNSODA database (Leij et al., 1999).

\section{Illinois Sites}

Figure 11 shows observed and simulated near-surface and subsurface soil moisture of the selected sites in Illinois (Fig. 2c) using the derived $\theta(h)$ and $K(h)$ functions (Table 5 ) in the forward simulations. Compared with the Oklahoma and Iowa sites, a longer time series of near-surface soil moisture data was available (Hollinger and Isard, 1994; Illinois State Water Survey, 2005) with at least one data point a month, thus providing more opportunities to capture the drier and wetter ranges of the soil hydraulic functions for the near-surface soil moisture assimilation scheme. The near-surface soil moisture was measured between 0 and $10 \mathrm{~cm}$ from the soil surface.
Overall, the near-surface soil moisture data were fitted well for all sites, with $R$ and MBE ranging from 0.74 to 0.93 and -0.032 to $0.012 \mathrm{~m}^{3} \mathrm{~m}^{-3}$, respectively. Correspondingly, the subsurface soil moisture data were reasonably fitted, with $R$ and MBE ranging from 0.79 to 0.99 and -0.057 to $0.085 \mathrm{~m}^{3} \mathrm{~m}^{-3}$, respectively. It is interesting to note here the subsurface soil moisture case of the Dixon Springs site (Fig. 11b.2), which showed a very high correlation between the observed and simulated subsurface soil moisture $(R=0.96)$, although the MBE was also high $\left(-0.057 \mathrm{~m}^{3}\right.$ $\mathrm{m}^{-3}$ ). The primary reason for this bias is the fact that the observed subsurface soil moisture was underestimated significantly during the dry season. This case could be a typical example of a modeling domain that cannot be represented well with an effective homogenous unit if only the near-surface soil moisture is used to estimate the effective soil hydraulic properties because of the high heterogeneity in the system. The parameter estimation process assumes that the estimated $\theta(h)$ and $K(h)$ functions using near-surface information are effective for the entire modeling domain. Evidently, this assumption may fall short when the soil is highly heterogeneous. The estimated soil hydraulic parameters appear to be good in the wetter range of the subsurface layers, but are inferior in the drier range (Fig. 11b.2). We did not have measured $\theta(h)$ data at the site to further validate the results; however, the UNSODA data show that the $\theta(b)$ estimate is a good reflection of silt loam soils. Figure 12 shows a comparison of the derived $\theta(b)$ data for Site 1-Bondville with the UNSODA data and the laboratory-measured $\theta(h)$ of a silt loam soil at the Oklahoma SGP97 site (near ARS-149). The estimated $K_{\text {sat }}$ values for the Dixon Springs and Brownstown sites (Table 5) were very low compared with the UNSODA data. The rainfall-soil moisture mismatch is still evident 
in some of the results (see Fig. 11a.1 and 13a). The weather data used in the simulations were collected from weather stations nearest to the monitoring sites (Table 2).
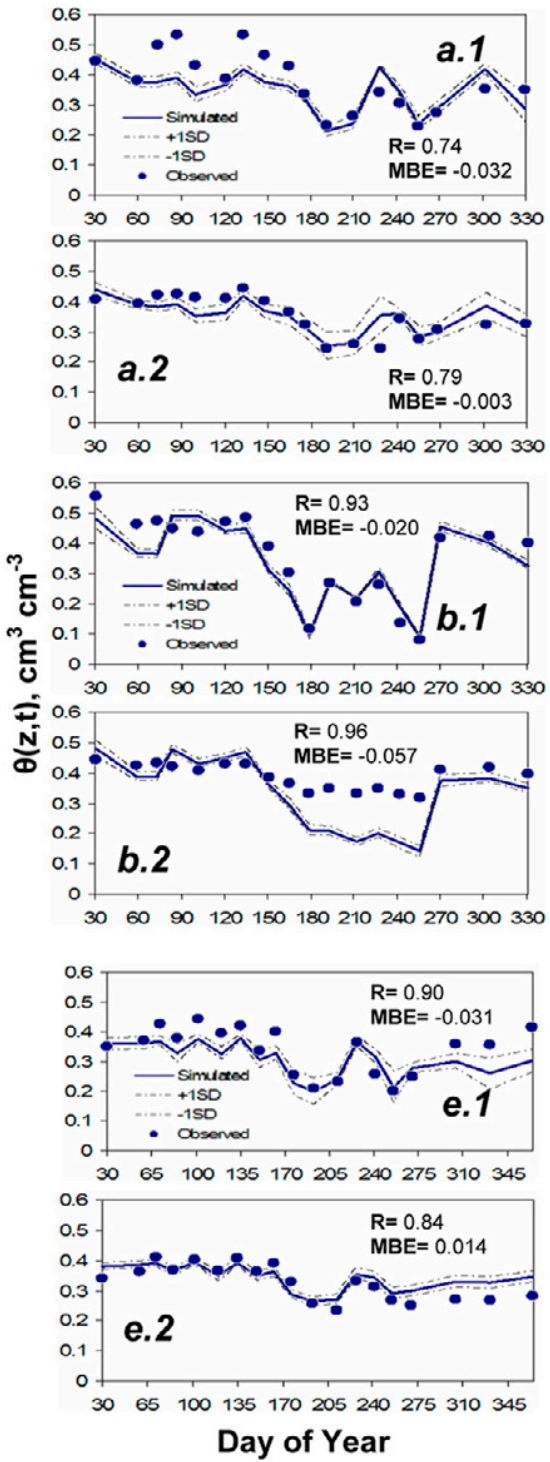

China Sites

Figure 14 shows the results for the selected sites in China (Fig. 2d). Here, we used quality-checked daily weather data (Feng et al., 2004) for the parameter estimation. Evidently, the proximity of the weather stations (due to spatial variation in rainfall) to the soil moisture sampling sites (Table 2) affected the results of the near-surface soil moisture assimilation. For Sites 33 (Nanyang) and 21 (Xifengzhen), the simulated and observed nearsurface soil moisture values were fitted well, having correlations $(R)$ of 0.93 and 0.78 , respectively. Although the MBE of the simulated and observed near-surface soil moisture for Site 15 (Shache) was similar to that of Sites 33 and 21, the random error was high (lower $R$ ) since the soil moisture dynamics did not closely follow the trend of rainfall at the site (Fig. 14b.1). In fact, at Site 15 , the only significant amount of rainfall recorded was $32 \mathrm{~mm}$ during DOY 178 (Fig. $13 \mathrm{~g}$ ). This site was situated near the Himalayan Mountains (western part of China), where possible overland and lateral subsurface flows from snowmelts may have affected the local soil moisture. For better results, exogenous sources of soil moisture like this should be explicitly included in the simulation model. Overall, the results for the China sites appear to be relatively good (Fig. 14). The majority of estimated soil hydraulic parameters (Table 6; crosscheck with Table 2 for soil texture) also appear to compare well with the UNSODA data (Leij et al., 1999). Since there were no measured $\theta(h)$ data available for these sites, we show a comparison of the measured $\theta(h)$ of a loam soil from the Oklahoma SGP97 site (ARS-135) with the GA-estimated $\theta(b)$ of Site 9 (Fuyu2), which is also a loam soil (Table 2). The estimated $\theta(b)$ of this site matched with the measured $\theta(b)$ from the SGP97 site with a similar

FIG. 11. Observed and simulated near-surface $(z=0-5 \mathrm{~cm})$ (top panels) and subsurface $(z=0-70 \mathrm{~cm})$ (bottom panels) soil moisture $\theta(z, t)$ for Illinois sampling sites in 2002: (a) 1-Bondville, (b) 2-Dixon Springs, (c) 3-Brownstown,

(d) 4-Orr Center, and (e) 5-De Kalb. MBE is mean bias error.

TABLE 5. Derived soil hydraulic parameters $\dagger$ for the selected Illinois sites.

\begin{tabular}{llccccc}
\hline \multicolumn{1}{c}{ Site } & Statistic & $\alpha$ & $n$ & $\theta_{\text {res }}$ & $\theta_{\text {sat }}$ & $K_{\text {sat }}$ \\
\hline \multirow{3}{*}{ 1-Bondville } & Mean & 0.014 & 1.263 & 0.120 & 0.454 & 10.9 \\
& CD & 0.007 & 0.051 & 0.018 & 0.016 & 6.7 \\
2-Dixon Springs & Mean & 0.010 & 1.603 & 0.062 & 0.492 & 2.3 \\
& SD & 0.002 & 0.007 & 0.001 & 0.013 & 0.6 \\
3-Brownstown & Mean & 0.008 & 1.602 & 0.062 & 0.594 & 2.7 \\
& SD & 0.003 & 0.018 & 0.001 & 0.008 & 0.7 \\
4-Orr Center & Mean & 0.013 & 1.408 & 0.069 & 0.544 & 18.6 \\
& SD & 0.004 & 0.069 & 0.015 & 0.041 & 12.4 \\
5-De Kalb & Mean & 0.018 & 1.471 & 0.130 & 0.533 & 14.4 \\
& SD & 0.007 & 0.094 & 0.025 & 0.028 & 4.8 \\
\hline
\end{tabular}

$\dagger \alpha$ is a shape parameter equivalent to the inverse of the bubbling pressure, $n$ is a shape parameter that accounts for the pore size distribution, $\theta_{\text {res }}$ and $\theta_{\text {sat }}$ are the residual and saturated soil moisture content respectively, $K_{\text {sat }}$ is the saturated hydraulic conductivity.

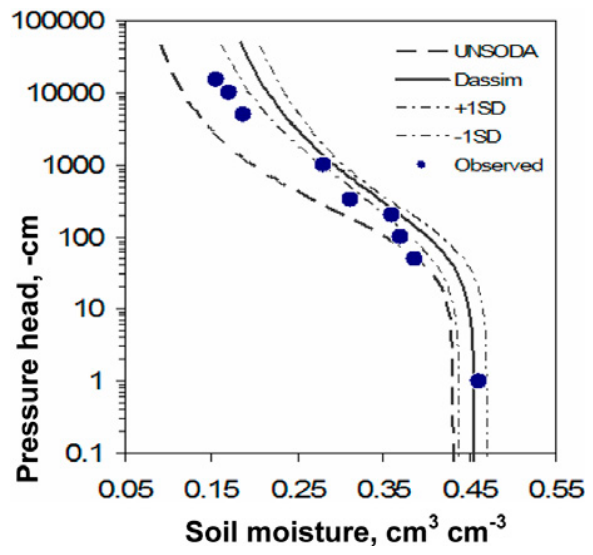

FIG. 12. Derived effective water retention $\mathrm{q}(\mathrm{h})$ for the Illinois sampling site 1-Bondville compared with a similar soil type (silt loam) from the Oklahoma Southern Great Plains 1997 (SGP97) site (near ARS-149). Dassim denotes predicted by the inverse modeling-based near-surface soil moisture assimilation scheme. 
texture extremely well (Fig. 15), thereby further supporting our hypothesis that soils with same texture should behave similarly. The good estimate of $\theta(b)$ may be attributed to the quality of the data (with long-duration monitoring at discrete depths) used for the near-surface soil moisture assimilation.

\section{Conclusions}

We conducted a field validation study for a newly developed GA-based inverse modeling near-surface soil moisture assimilation scheme for estimating the effective soil hydraulic properties from different hydroclimatic regions, namely the SGP97 sites in Oklahoma, the SMEX02 sites in Iowa, and soil moisture monitoring sites in Illinois, as well as for several sites in China. We used measured near-surface soil moisture data to estimate the effective Mualem-van Genuchten soil hydraulic functions $\theta(b)$ and $K(b)$ of the effective modeling domain. A GA was used to derive the appropriate parameter combinations of $\alpha, n, \theta_{\text {res }}$, $\theta_{\text {sat }}$, and $K_{\text {sat }}$ by minimizing the difference between the measured near-surface soil moisture data and the simulated values obtained with a physically based model of the soil-water-atmosphere-plant system (SWAP).

Under actual field conditions, the uncertainties involved in prescribing the initial and bottom boundary conditions, root- ing depth, and root density were considered in the parameter estimation process. We also used a multipopulation approach in the GA to estimate the uncertainty of the parameter estimates. Results show that the soil water retention curve $\theta(h)$ was relatively insensitive to variations in the modeling domains. Some of the experiments showed, however, that the hydraulic conductivity $K(h)$ estimates can be quite sensitive to rooting depth and root density variations. The effects of varying conditions in the modeling domain on the profile soil moisture $\theta(z, t)$ were apparent because of a change in the hydrologic regime. In certain cases, even though the near-surface soil moisture was fitted well, the discrepancies in subsurface soil moisture suggest that the effective modeling domain could not be well represented. Variations in the initial and bottom boundary conditions, rooting depth, and root density were used in finetuning the solutions.

The validation data used in this study included the measured or derived soil hydraulic parameters using laboratory-measured $\theta(b)$ and $K_{\text {sat }}$ values, field measurements of surface and subsurface soil moisture, and soil hydraulic properties from the UNSODA database. Overall, the solutions from the near-surface soil moisture assimilation scheme are promising since the estimated parameters did well in reproducing the measured values, especially in the drier parts of $\theta(h)$ and $K(h)$. For some soil types, (e.g., loam soil), the $K_{\text {sat }}$ value was also well determined. The simulated and measured near-surface and subsurface soil moisture contents were reasonably fitted in some sites and regions but not for others because of several factors not accounted for in the simulations. Overall, compared with the UNSODA data and texturebased effective soil hydraulic property estimates, the inversely estimated $\theta(h)$ matched the measured $\theta(b)$ better in the specific experimental locations.

In this validation study, we identified several issues that could affect the performance of the parameter estimation scheme. We observed that the duration (data volume), observation depth, and information content (data range and variability) of the near-surface soil moisture data are crucial for successful parameter estimation. Data mismatch such as incurred in the timing of soil moisture sampling and the occurrence of rainfall could also affect the performance of the parameter estimation process. Exogenous sources of soil moisture (e.g., snowmelt that cannot be accounted for as inputs in the SWAP modeling) would impact the inverse solutions as well. Additionally, the proximity of the weather station to the soil monitoring site as well as spatial variability in precipitation may affect the soil hydraulic parameter estimation results. Uncertainty in the soil hydrologic model, the daily time step used in the simulations, and the sensitivity of the soil hydraulic parameters to the fitness function used in the GA could also affect the inverse solutions. Finally, a critique of the assumption of an effective homogenous soil unit to represent a heterogeneous profile is postulated. Based on some of our results, it appears
FIG. 13. Rainfall data for the Illinois sites in 2002 and the China sites in 1992: (a) 1-Bondville, (b) 2-Dixon Springs, (c) 3-Brownstown, (d) 4-Orr Center, (e) 5-De Kalb, (f) 9-Fuyu2, (g) 15-Shache, (h) 21-Xifengzhen, (i) 33-Nanyang, and (j) 36-Xuzhou. 


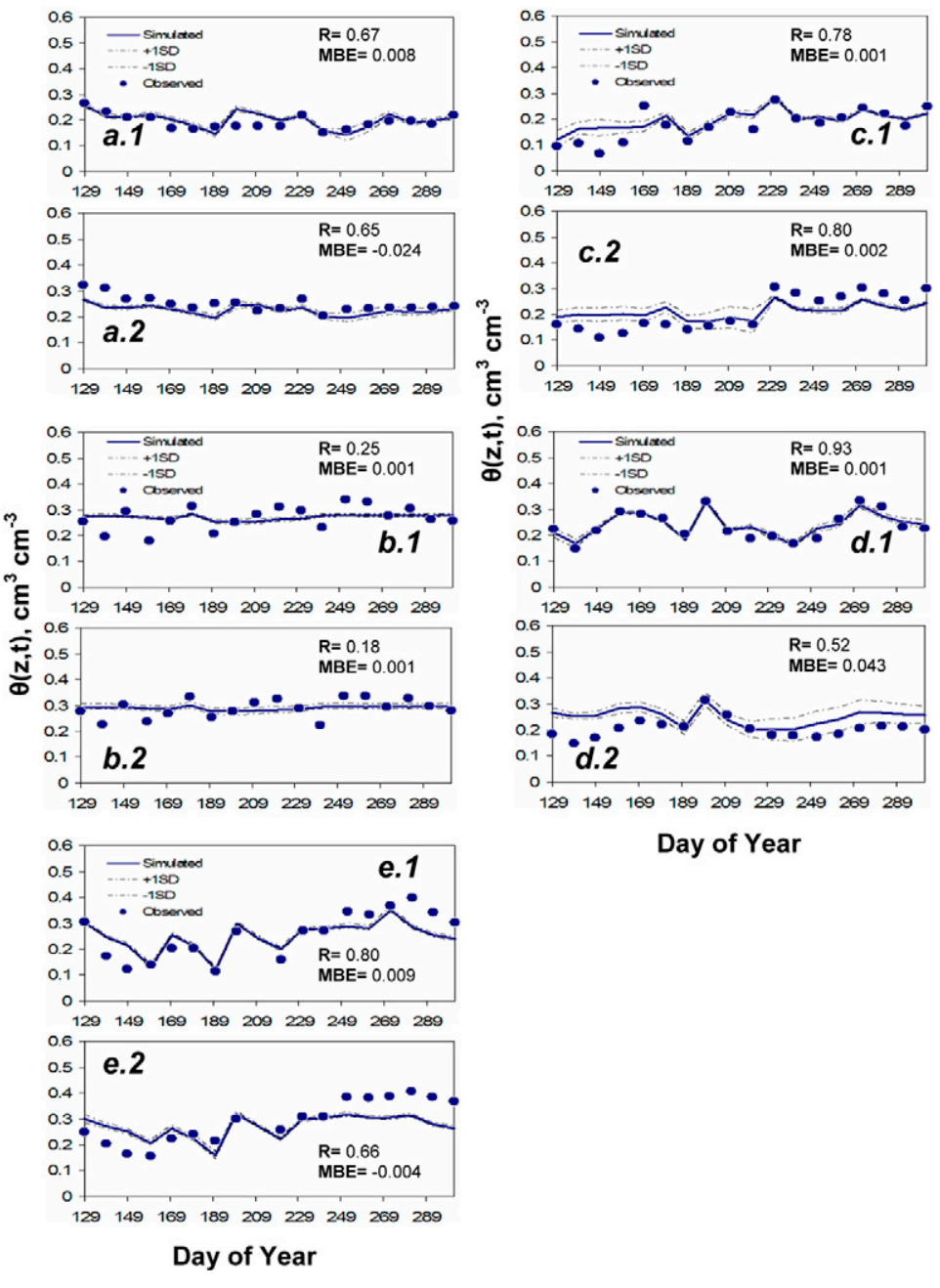

FIG. 14. Observed and simulated near-surface $(z=0-5 \mathrm{~cm})$ (top panels) and subsurface $(z=0-60 \mathrm{~cm})$ (bottom panels) soil moisture $\theta(z, t)$ for the China sampling sites in 1992: (a) 9-Fuyu2, (b) 15-Shache, (c) 21-Xifengzhen, (d) 33-Nanyang, and (e) 36-Xuzhou. $\mathrm{MBE}$ is mean bias error.

TABLE 6. Derived soil hydraulic parameters $†$ for the selected China sites.

\begin{tabular}{llccccc}
\hline \multicolumn{1}{c}{ Site } & Statistic & $\alpha$ & $n$ & $\theta_{\text {res }}$ & $\theta_{\text {sat }}$ & $K_{\text {sat }}$ \\
\hline \multirow{3}{*}{ 9-Fuyu2 } & & $\mathrm{cm}^{-1}$ & & $-\mathrm{m}^{3}$ & $\mathrm{~m}^{-3}-$ & $\mathrm{cm} \mathrm{d}^{-1}$ \\
& Mean & 0.024 & 1.604 & 0.073 & 0.373 & 55.3 \\
15-Shache & SD & 0.007 & 0.006 & 0.022 & 0.005 & 0.7 \\
& Mean & 0.015 & 1.589 & 0.102 & 0.401 & 42.2 \\
\multirow{2}{*}{ 21-Xifengzhen } & SD & 0.006 & 0.016 & 0.031 & 0.026 & 10.7 \\
& Mean & 0.032 & 1.604 & 0.062 & 0.390 & 24.9 \\
33-Nanyang & SD & 0.001 & 0.006 & 0.001 & 0.021 & 11.1 \\
& Mean & 0.027 & 1.517 & 0.099 & 0.433 & 12.8 \\
& SD & 0.004 & 0.072 & 0.009 & 0.036 & 11.9 \\
& Mean & 0.028 & 1.596 & 0.063 & 0.401 & 9.3 \\
& SD & 0.005 & 0.034 & 0.002 & 0.044 & 13.6 \\
\hline
\end{tabular}

$\dagger \alpha$ is a shape parameter equivalent to the inverse of the bubbling pressure, $n$ is a shape parameter that accounts for the pore size distribution, $\theta_{\text {res }}$ and $\theta_{\text {sat }}$ are the residual and saturated soil moisture content respectively, $K_{\text {sat }}$ is the saturated hydraulic conductivity.

that an effective homogenous soil unit may fail to accurately represent a highly heterogeneous soil profile if only near-surface soil moisture data is used to estimate the effective soil hydraulic properties.

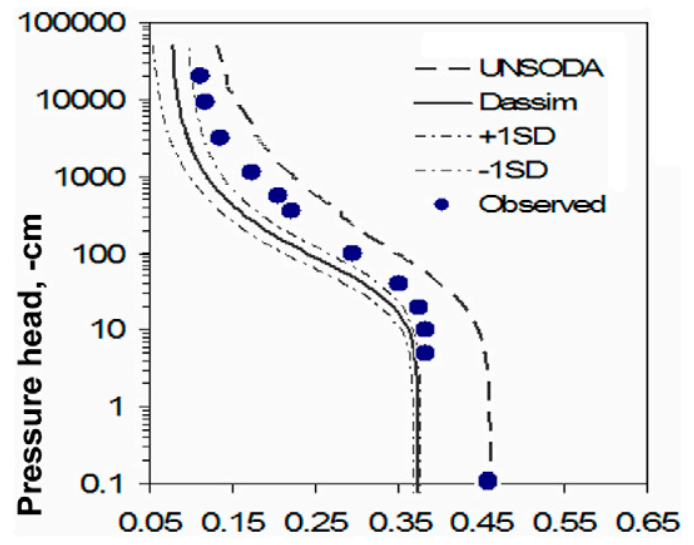

Soil moisture, $\mathrm{cm}^{3} \mathrm{~cm}^{-3}$

FIG. 15. Derived effective water retention $\theta(h)$ for Site 9 (Fuyu2) in China compared with a similar soil type (loam) from the Oklahoma Southern Great Plains 1997 (SGP97) site (ARS-135). Dassim denotes predicted by the inverse modeling-based near-surface soil moisture assimilation scheme.

\section{ACKNOWLEDGMENTS}

This research was funded by NASA-GAPP Grant NNG04GM35G. We would like to acknowledge partial support of LANL-SAHRA, NASA (Grant TEES no. 35410), and NSF (CMG/DMS grant) for this work. We acknowledge the use of the USDA-ARS micronet and Oklahoma mesonet data, SCAN and Iowa mesonet data, and the Illinois Climate Network data. We acknowledge also the use of the Global Soil Moisture Databank of Rutgers University. R. Scott is acknowledged for his help on the Illinois data sets, and S. Feng and Q. Hu for allowing us to use their Chinese daily weather data.

\section{References}

Abbaspour, K.C., R. Kasteel, and R. Schulin. 2000. Inverse parameter estimation in a layered unsaturated field soil. Soil Sci. 165:109-123.

Bastiaanssen, W.G.M., M.D. Ahmad, and Y. Chemin. 2002. Satellite surveillance of evaporative depletion across the Indus Basin. Water Resour. Res. 38:1273-1282.

Belmans, C., J.G. Wesseling, and R.A. Feddes. 1983. Simulation of water balance of a cropped soil: SWATRE. J. Hydrol. 63:271-286.

Bertuzzi, P., and L. Bruckler. 1996. A scaling based estimation of soil unsaturated hydraulic properties at a field scale. Irrig. Sci. 17:23-30.

Carroll, D.L. 1998. Fortran genetic algorithm (GA) driver. Available at www. cuaerospace.com/carroll/ga.html (verified 27 Nov. 2007). CU Aerospace, Champaign, IL.

Capehart, W.J., and T.N. Carlson. 1997. Decoupling of surface and near-surface soil water content: A remote sensing perspective. Water Resour. Res. 33:1383-1395.

Clausnitzer, V., J.W. Hopmans, and D.R. Nielsen. 1992. Simultaneous scaling of soil water retention and hydraulic conductivity curves. Water Resour. Res. 26:1483-1496.

Crow, W.T., and E.F. Wood. 2003. The assimilation of remotely sensed soil brightness temperature imagery into a land surface model using Ensemble Kalman filtering: A case study based on ESTAR measurements during SGP97. Adv. Water Resour. 26:137-149.

Das, N.N., and B.P. Mohanty. 2006. Root zone soil moisture assessment using remote sensing and vadose zone modeling. Vadose Zone J. 5:296-307.

Dunne, S., and D. Entekhabi. 2005. An ensemble-based reanalysis approach to land data assimilation. Water Resour. Res. 41:W02013, doi:10.1029/ 2004WR003449.

Entekhabi, D., H. Nakamura, and E.G. Njoku. 1994. Solving the inverse problem for soil moisture and temperature profiles by sequential assimilation of multifrequency remotely sensed observations. IEEE Trans. Geosci. Remote Sens. 32:438-448. 
Feddes, R.A., G.H. De Rooij, J.C. Van Dam, P. Kabat, and P. Droogers. 1993a. Estimation of regional effective soil hydraulic parameters by inverse modeling. p. 211-233. In D. Russo and G. Dagan (ed.) Water flow and solute transport in soils. Adv. Ser. in Agric. Sci. 20. Springer-Verlag, Berlin.

Feddes, R.A., M. Menenti, P. Kabat, and W.G.M. Bastiaanssen. 1993b. Is largescale inverse modeling of unsaturated flow with areal average evaporation and surface soil moisture as estimated by remote sensing feasible? J. Hydrol. 143:125-152.

Feng, S., Q. Hu, and W. Qian. 2004. Quality control of daily meteorological data in China, 1951-2000: A new dataset. Int. J. Climatol. 24:853-870.

Galantowicz, J.F., D. Entekhabi, and E.G. Njoku. 1999. Tests of sequential data assimilation for retrieving profile soil moisture and temperature from observed L-band radiobrightness. IEEE Trans Geosci. Remote Sens. 37:1860-1870

Goldberg, D.E. 1989. Genetic algorithms in search and optimization and machine learning. Addison-Wesley, Boston, MA.

Goldberg, D.E. 2002. The design of innovation: Lessons from and for competent genetic algorithms. Kluwer Academic, Norwell, MA.

Gomez-Hernandez, J.J., and S.M. Gorelick. 1989. Effective groundwater model parameter values: Influence of spatial variability of hydraulic conductivity, leakage, and recharge. Water Resour. Res. 25:405-419.

Green, T.R., J.E. Contantz, and D.L. Freyberg. 1996. Upscaled soil water retention using van Genutchten's function. J. Hydrol. Eng. 1:123-130.

Heathman, G.C., P.J. Starks, L.R. Ahuja, and T.J. Jackson. 2003. Assimilation of surface soil moisture to estimate profile soil water content. J. Hydrol. 279:1-17.

Holland, J.H. 1975. Adaptation in natural and artificial systems. Univ. of Michigan Press, Ann Arbor.

Hollinger, S.E., and S.A. Isard. 1994. A soil moisture climatology of Illinois. J. Clim. 7:822-833.

Hopmans, J.W., and J.N.M. Stricker. 1989. Stochastic analysis for soil water regime in a watershed. J. Hydrol. 105:57-84.

Illinois State Water Survey. 2005. Water and atmospheric resources monitoring (WARM) program, Illinois climate network. Illinois State Water Survey, Champaign.

Ines, A.V.M., and P. Droogers. 2002a. Inverse modeling in estimating soil hydraulic functions: A genetic algorithm approach. Hydrol. Earth Syst. Sci. 6:49-65.

Ines, A.V.M., and P. Droogers. 2002b. Inverse modeling to quantify irrigation system characteristics and operational management. Irrig. Drain. Syst. $16: 233-252$.

Ines, A.V.M., and K. Honda. 2005. On quantifying agricultural and water management practices from low spatial resolution RS data using genetic algorithms: A numerical study for mixed pixel environment. Adv. Water Resour. 28:856-870.

Jackson, T.J. 2002. SMEX02 Soil Climate Analysis Network (SCAN) Station 2031, Ames, Iowa. Natl. Snow and Ice Data Ctr., Boulder, CO.

Jackson, T.J., D.M. Le Vine, T.J. Schmugge, and F.R. Schiebe. 1995. Large area mapping of soil moisture using ESTAR passive microwave radiometer in Washita '92. Remote Sens. Environ. 53:27-37.

Jacobs, J.M., B.P. Mohanty, E.C. Hsu, and D. Miller. 2004. SMEX02: Field scale variability, time stability and similarity of soil moisture. Remote Sens. Environ. 92:436-446.

Jhorar, R.K., W.G.M. Bastiaanssen, R.A. Feddes, and J.C. Van Dam. 2002. Inversely estimating soil hydraulic functions using evapotranspiration fluxes. J. Hydrol. 258:198-213.

Jhorar, R.K., J. Van Dam, W.G.M. Bastiaanssen, and R.A. Feddes. 2004. Calibration of effective soil hydraulic parameters of heterogenous soil profiles. J. Hydrol. 285:233-247.

Kabat, P., R.W.A. Hutjes, and R.A. Feddes. 1997. The scaling characteristics of soil parameters: From plot scale heterogeneity to subgrid parameterization. J. Hydrol. 190:363-396.

Kool, J.B., and J.C. Parker. 1988. Analysis of the inverse problem for transient unsaturated flow. Water Resour. Res. 24:817-830.

Krishnakumar, K. 1989. Microgenetic algorithms for stationary and nonstationary function optimization. p. 289-296. In G. Rodriguez (ed.) Intelligent control and adaptive systems. Proc. SPIE 1196. SPIE, Philadelphia, PA.

Leij, F.J., W.J. Alves, M.Th. van Genuchten, and J.R. Williams. 1999. The UNSODA unsaturated soil hydraulic database. p. 1269-1281. In M.Th. van Genuchten et al. (ed.) Characterization and measurement of the hydraulic properties of unsaturated porous media. Univ. of California, Riverside.

Li, H., A. Robock, S. Liu, X. Mo, and P. Viterbo. 2005. Evaluation of reanalysis soil moisture simulations using updated Chinese soil moisture observations. J. Hydrometeorol. 6:180-193.

Miller, E.E., and R.D. Miller. 1956. Physical theory of capillary flow phenomena. J. Appl. Phys. 27:324-332.

Mohanty, B.P., D.A. Miller, and M.Th. van Genuchten. 2002. Soil property database: Southern Great Plains 1997 hydrology experiment. Water Resour. Res. 38:1047, doi:10.1029/2000WR000076.

Mohanty, B.P., and T.H. Skaggs. 2001. Spatio-temporal evolution and time-stable characteristics of soil moisture within remote sensing footprints with varying soil, slope, and vegetation. Adv. Water Resour. 24:1051-1067.

Mohanty, B.P., and J. Zhu. 2007. Effective soil hydraulic parameters in horizontally and vertically heterogeneous soils for steady-state land-atmosphere interaction. J. Hydrometeorol. 8:715-729.

Mualem, Y. 1976. A new model for predicting the hydraulic conductivity of unsaturated porous media. Water Resour. Res. 12:513-522.

Robock, A., K.Y. Vinnikov, G. Srinivasan, J.K. Entin, S.E. Hollinger, N.A. Speranskaya, S. Liu, and A. Namkhai. 2000. The global soil data bank. Bull. Am. Meteorol. Soc. 81:1281-1299.

Rockhold, M.L., R.E. Rossi, and R.G. Hills. 1996. Application of similar media scaling and conditional simulation for modeling water flow and tritium transport at the Las Cruces trench site. Water Resour. Res. 32:595-609.

Van Dam, J.C. 2000. Field-scale water flow and solute transport. SWAP model concepts, parameter estimation and case studies. Ph.D. diss. Wageningen Univ., Wageningen, the Netherlands.

Van Dam, J.C., J. Huygen, J.G. Wesseling, R.A. Feddes, P. Kabat, P.E.V. Van Waslum, P. Groenendjik, and C.A. Van Diepen. 1997. Theory of SWAP version 2.0: Simulation of water flow and plant growth in the soil-wateratmosphere-plant environment. Tech. Doc. 45. Wageningen Agric. Univ. and DLO Winand Staring Centre, Wageningen, the Netherlands.

van Genuchten, M.Th. 1980. A closed-form equation for predicting the hydraulic conductivity of unsaturated soils. Soil Sci. Soc. Am. J. 44:892-898.

Vrugt, J.A., G. Schoups, J.W. Hopmans, C. Young, W.W. Wallender, and W. Bouten. 2004. Inverse modeling of large-scale spatially distributed vadose zone properties using global optimization. Water Resour. Res. 40:W06503, doi:10.1029/2003WR00276.

Walker, J.P., G.R. Willgoose, and J.D. Kalma. 2001. One-dimensional soil moisture profile retrieval by assimilation of near-surface observations: A comparison of retrieval algorithms. Adv. Water Resour. 24:631-650.

Wood, E.F. 1994. Scaling, soil moisture and evapotranspiration in runoff models. Adv. Water Resour. 17:24-34.

Wu, J., C. Zheng, C. Chein, and L. Zheng. 2006. A comparative study of Monte Carlo simple genetic algorithm and noisy genetic algorithm for cost-effective sampling network design under uncertainty. Adv. Water Resour. 29:899-911.

Zhu, J.T., and B.P. Mohanty. 2002. Spatial averaging of van Genuchten hydraulic parameters for steady state flow in heterogeneous soils: A numerical study. Vadose Zone J. 1:261-272.

Zhu, J.T., and B.P. Mohanty. 2003. Effective hydraulic parameters for steady state vertical flow in heterogeneous soils. Water Resour. Res. 39(8):1227, doi:10.1029/2002WR001831. 